\title{
Characterization of adipose-derived stem cells from subcutaneous and visceral adipose tissues and their function in breast cancer cells
}

\author{
Andreas Ritter ${ }^{1}$, Alexandra Friemel ${ }^{1}$, Friderike Fornoff ${ }^{1}$, Mouhib Adjan ${ }^{1}$, Christine \\ Solbach ${ }^{1}$, Juping Yuan ${ }^{1, *}$ and Frank Louwen ${ }^{1, *}$ \\ ${ }^{1}$ Department of Gynecology and Obstetrics, School of Medicine, J. W. Goethe-University, Frankfurt, Germany \\ * These authors have equal contribution as last author \\ Correspondence to: Juping Yuan, email: yuan@em.uni-frankfurt.de \\ Keywords: adipose-derived stem cells, breast cancer cells, epithelial-to-mesenchymal transition, invasion, drug resistance \\ Received: July 28, $2015 \quad$ Accepted: September 08, $2015 \quad$ Published: September 30, 2015
}

This is an open-access article distributed under the terms of the Creative Commons Attribution License, which permits unrestricted use, distribution, and reproduction in any medium, provided the original author and source are credited.

\section{ABSTRACT}

Adipose-derived stem cells are capable of differentiating into multiple cell types and thus considered useful for regenerative medicine. However, this differentiation feature seems to be associated with tumor initiation and metastasis raising safety concerns, which requires further investigation. In this study, we isolated adiposederived stem cells from subcutaneous as well as from visceral adipose tissues of the same donor and systematically compared their features. Although being characteristic of mesenchymal stem cells, subcutaneous adipose-derived stem cells tend to be spindle form-like and are more able to home to cancer cells, whereas visceral adiposederived stem cells incline to be "epithelial"-like and more competent to differentiate. Moreover, compared to subcutaneous adipose-derived stem cells, visceral adiposederived stem cells are more capable of promoting proliferation, inducing the epithelial-to-mesenchymal transition, enhancing migration and invasion of breast cancer cells by cell-cell contact and by secreting interleukins such as IL-6 and IL8. Importantly, ASCs affect the low malignant breast cancer cells MCF-7 more than the highly metastatic MDA-MB-231 cells. Induction of the epithelial-to-mesenchymal transition is mediated by the activation of multiple pathways especially the PI3K/ AKT signaling in breast cancer cells. BCL6, an important player in B-cell lymphoma and breast cancer progression, is crucial for this transition. Finally, this transition fuels malignant properties of breast cancer cells and render them resistant to ATP competitive Polo-like kinase 1 inhibitors BI 2535 and BI 6727.

\section{INTRODUCTION}

Breast cancer is the second most common cancer worldwide with 1.7 million cases and over 522,000 deaths per year [1]. During the last years, numerous investigations have reported a complex signaling network between breast cancer cells and the tumor microenvironment which affects tumor malignance and therapeutic responsiveness [2]. Adipose tissue, a metabolically active endocrine organ, is the most abundant stromal constituent in the mammary gland surrounding breast cancer. This tissue shows a high secretive activity and is an extensive source of mesenchymal stem cells (MSCs) or more specifically adipose-derived stem/stroma cells (ASCs). ASCs are capable of differentiating into multiple cell types such as adipocytes, neurons, osteoblasts and retain the ability of self-renewing [3]. By virtue of their regenerative features like pro-angiogenic, anti-apoptotic, pro-proliferative and multipotent differentiation, ASCs are widely considered as a promising tool for regenerative medicine application and tissue engineering [4,5], such as breast reconstruction after breast ablation in cancer patients. Unfortunately, the 
Table 1: Clinical information of 10 patients

\begin{tabular}{|l|l|l|l|l|}
\hline & age & $\begin{array}{l}\text { gestational } \\
\text { age (weeks) }\end{array}$ & $\begin{array}{l}\text { body mass } \\
\text { index } \\
\text { (BMI) }\end{array}$ & $\begin{array}{l}\text { birth weight } \\
(\mathbf{g})\end{array}$ \\
\hline patients & $33.6 \pm 3.3$ & $38.2 \pm 2.6$ & $22.0 \pm 2.5$ & $3295 \pm 666$ \\
\hline
\end{tabular}

same features of ASCs that induce tissue regeneration and vascularization are also assumed to be associated with tumor initiation and metastasis [6] raising safety concerns about clinical utilization. Therefore, ASCs have been intensively investigated for their role in cancer cell proliferation, migration and metastasis [7]. While numerous investigations indicate that ASCs promote tumor growth and malignant phenotypes in multiple cancer types [7], supported by in vivo studies showing increased tumor growth, metastatic spread and angiogenesis [7, 8], other studies reveal a therapeutic potential of ASCs in breast cancer models in vitro and in vivo $[9,10]$.

To further delineate the relationship between ASCs and cancer progression, we have isolated ASCs from visceral and subcutaneous adipose tissue collected from female donors undergoing caesarian section, characterized their features and studied their impact on breast cancer cells. To exclude variations between isolated ASCs from different donors, we performed most of the studies with paired visceral and subcutaneous ASCs of the same donor with a comprehensive number. Our study reveals distinct properties of these two types of ASCs with varied effects on cancer cells. Interestingly, visceral ASCs are more potent to induce the epithelial-to-mesenchymal transition in breast cancer cells mediated by activating multiple pathways in particular the PI3K/AKT signaling.

\section{RESULTS}

\section{Visceral and subcutaneous ASCs display distinct morphologies and multipotent differentiation potential}

ASCs were isolated from visceral and subcutaneous adipose tissues, using a well-established method [11], from female donors undergoing caesarian sections (Table 1). These two types of ASCs displayed distinct morphologies at their early passages 1-3: visceral ASCs were more "epithelial"-like with an apical-basal polarity of the tubulin and vimentin cytoskeleton (Figure 1A, $1^{\text {st }}$ panel), whereas subcutaneous ASCs were more characteristic of a fibroblast-like morphology with a small cell body (Figure 1A, $2^{\text {nd }}$ panel). Yet, ASCs isolated from both sources exhibited typical cell surface markers for mesenchymal stem cells described by the Society for Cellular Therapy [11, 12]: positive for CD90, CD73, CD146 and highly negative for CD14, CD31, CD106 and
CD34 measured by flow cytometry (Table 2). Indirect immunofluorescence staining in ASCs further underscored the positive signals of CD90 and CD73 (Figure 1B), which were negative in $\mathrm{MCF}-7$ cells (Figure S1A). In addition, the signals of CD14 and CD31 were undetectable in ASCs using immunofluorescence staining (Figure S1B). ASCs were then induced into adipogenic, neurogenic and osteogenic cells, and the in vitro differentiation potential was determined by lineage-specific staining. After 14 days of neurogenic induction, $43 \%$ of visceral ASCs showed lineage specific staining of Tuj1, a marker for class III $\beta$-tubulin, and DCX, a marker for developing neurons, in addition to neuronal branching among differentiated cells (Figure 1C, $1^{\text {st }}$ panel and Figure 1D). 34\% of visceral ASCs were positively stained for adiponectin, one of the adipokines secreted by adipocytes, confirming the adipogenic differentiation capacity (Figure $1 \mathrm{C}, 2^{\text {nd }}$ panel and Figure 1D). The osteogenic differentiation was verified by alizarin red S staining in $15 \%$ of cells (Figure $1 \mathrm{C}, 3^{\text {rd }}$ panel and Figure 1D). All these differentiation markers were negative in non-differentiated ASCs (Figure S1C). Moreover, compared to visceral ASCs, subcutaneous ASCs of the same donor displayed less differentiating capability by showing only $37 \%$ positive in neuronal markers, $29 \%$ in adipogenic markers and $9 \%$ in alizarin red S (Figure S1D), indicating that these two types of ASCs exhibit not only varied morphology but also different differential potential.

\section{ASCs secrete various factors and are attracted to breast cancer cells}

As mesenchymal stem cells are a source of many secreted cytokines, chemokines and growth factors [13], we analyzed next these factors in conditioned media from cultured ASCs with human cytokine arrays. Indeed, the array assay underscored the secretion of various cytokines, chemokines and growth factors by both types of ASCs (Table 3), especially IL-6, GRO, IL-8, IL-10, agiogenin and CCL5 showed high expression levels (Figure 2A). The secretion pattern of visceral and subcutaneous ASCs was very similar, however, the expression level varied between these two types of ASCs. Compared to subcutaneous ASCs, visceral ASCs were clearly more capable of secreting these factors (Table 3 and Figure 2A). Most of the detected secreted factors are known to be involved in cancer cell proliferation and progression [14].

Many studies have reported a tropism of ASCs toward cancer cells [15]. To underline this observation, 
Table 2: Cell surface markers of ASCs

\begin{tabular}{|c|c|c|c|c|c|c|c|}
\hline \multirow[b]{2}{*}{ Patient No.: } & \multicolumn{7}{|c|}{ Cell surface markers in \% } \\
\hline & CD90 & CD73 & CD146 & CD14 & CD31 & CD106 & CD34 \\
\hline No. 1: ASCvis & 62.88 & 45.58 & 8.46 & 6.90 & 0.61 & 0.84 & ND. \\
\hline ASCsub & 76.92 & 90.13 & 18.84 & 7.20 & 2.03 & 1.63 & ND. \\
\hline No. 2: ASCvis & 96.39 & 92.04 & 18.33 & 8.57 & 2.50 & 2.14 & ND. \\
\hline ASCsub & 75.39 & 94.63 & 23.07 & 0.20 & 1.11 & 1.04 & ND. \\
\hline No. 3: ASCvis & 62.14 & 75.89 & 49.28 & 2.02 & 2.55 & 2.08 & ND. \\
\hline ASCsub & 58.65 & 94.00 & 49.75 & 0.50 & 2.60 & 2.12 & ND. \\
\hline No. 4: ASCvis & 81.84 & 55.17 & 3.89 & 16.77 & 2.49 & 0.23 & 1.97 \\
\hline ASCsub & 81.36 & 74.52 & 6.07 & 10.54 & 2.44 & 1.39 & 2.64 \\
\hline No. 5: ASCvis & 64.69 & 97.37 & 79.33 & 0.67 & 2.88 & 6.84 & 0.18 \\
\hline ASCsub & 88.72 & 64.34 & 71.72 & 3.22 & 0.64 & 0.54 & 4.36 \\
\hline No. 6: ASCvis & 38.47 & 58.02 & 50.43 & 11.94 & 1.51 & 5.94 & 0.04 \\
\hline ASCsub & 97.67 & 91.37 & 75.24 & 1.47 & 2.60 & 5.73 & 0.17 \\
\hline No. 7: ASCvis & 91.60 & 33.09 & 18.94 & 1.05 & 1.99 & 5.14 & 1.07 \\
\hline ASCsub & 47.47 & 87.99 & 30.45 & 7.95 & 1.85 & 4.94 & 0.89 \\
\hline No. 8: ASCvis & 89.66 & 94.01 & 84.59 & 2.60 & 2.02 & 1.86 & ND. \\
\hline ASCsub & 87.44 & 91.58 & 93.28 & 19.94 & 2.54 & 2.09 & ND. \\
\hline No. 9: ASCvis & 79.36 & 92.40 & 20.39 & 0.41 & 1.93 & 1.92 & ND. \\
\hline ASCsub & 9.86 & 94.31 & 29.58 & 0.13 & 1.70 & 9.45 & ND. \\
\hline No. 10: ASCvis & 80.42 & 72.11 & 58.96 & 5.93 & 0.95 & 1.78 & ND. \\
\hline ASCsub & 71.87 & 98.51 & 65.98 & 8.04 & 2.51 & 2.05 & ND. \\
\hline Mean value: & 72.14 & 79.85 & 42.83 & 5.80 & 1.97 & 2.99 & 1.41 \\
\hline SD value: & 21.54 & 19.23 & 28.53 & 5.71 & 0.69 & 2.47 & 1.50 \\
\hline
\end{tabular}

Values represent the percentage of ASCs expressing different surface specific markers.

ASCvis, visceral adipose-derived stem cells; ASCsub, subcutaneous adipose-derived stem cells,

ND., not determined.

we performed attraction assays, where we seeded visceral/ subcutaneous ASCs and breast cancer cells in separated chambers of a culture insert with a defined cell free gap between these two chambers. The number of membrane protrusions of ASCs toward cancer cells, including lamellipodia and filopodia, was evaluated evidencing the tropism of ASCs. Both types of ASCs, especially subcutaneous ASCs, showed an increased homing ability toward breast cancer cells MCF-7, MDA-MB-231, fibroblasts and cervical carcinoma HeLa cells during the time period of $15 \mathrm{~h}$ (Figure 2B and 2C, and Figure S2A and B). By contrast, the normal mammary epithelial MCF-10A cells were not able to attract these two types of ASCs (Figure 2B, right panel, and Figure 2C, panel 5 and 6). To corroborate these results, we stained MCF-7 and MDA-MB-231 cells after $15 \mathrm{~h}$ for migration markers acetylated $\alpha$-tubulin, phospho-Focal Adhesion Kinase (p-FAK) and phalloidin. The staining of phalloidin as well as p-FAK illustrated cytoskeleton protrusion of both ASC types, in particular subcutaneous ASCs, toward MCF-7 or MDA-MB-231 cells (Figure 2D). Interesting, the staining of acetylated $\alpha$-tubulin was highly intensified on the connections between ASCs and breast cancer cells, likely to stabilize these new formed interactions (Figure 2D). Collectively, the data indicate that ASCs can interact with cancer cells directly via cell-cell connections and indirectly by the secretion of various soluble factors.

\section{Enhanced proliferation of breast cancer cells following direct co-culture with ASCs}

To address if ASCs have an effect on the proliferation of cancer cell lines, we performed cell viability assays. To determine the optimal ASC concentration, cell viability assays were performed with MCF-7 cells in the presence of increased ASC concentrations $(5 \%, 10 \%, 15 \%, 20 \%, 30 \%) .20 \%$ of ASCs was taken for further investigations as it displayed the strongest promotion in MCF-7 cell proliferation (Figure S2C). In a direct co-culture manner with $20 \%$ of ASCs, the viability of breast cancer cells together with 
A
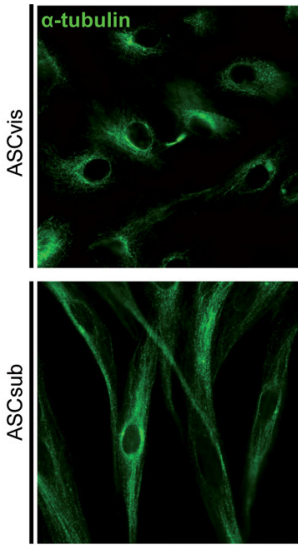

B
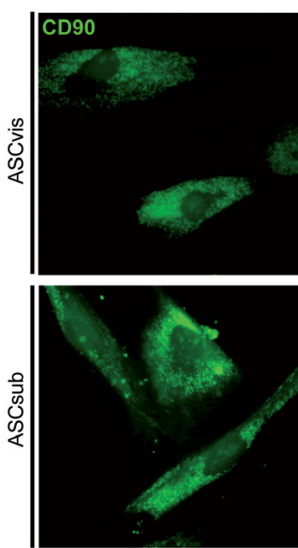

C
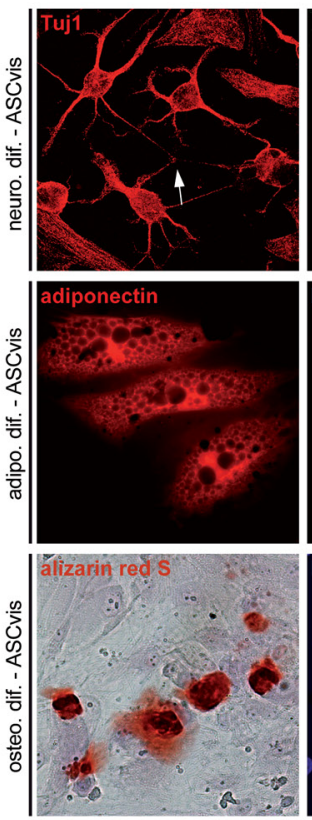
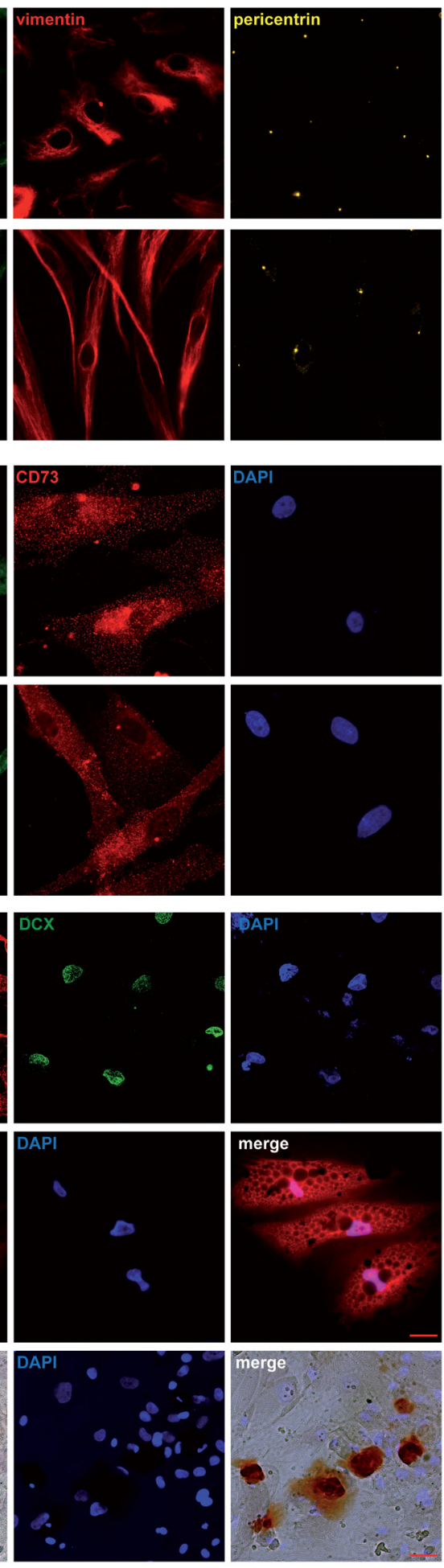
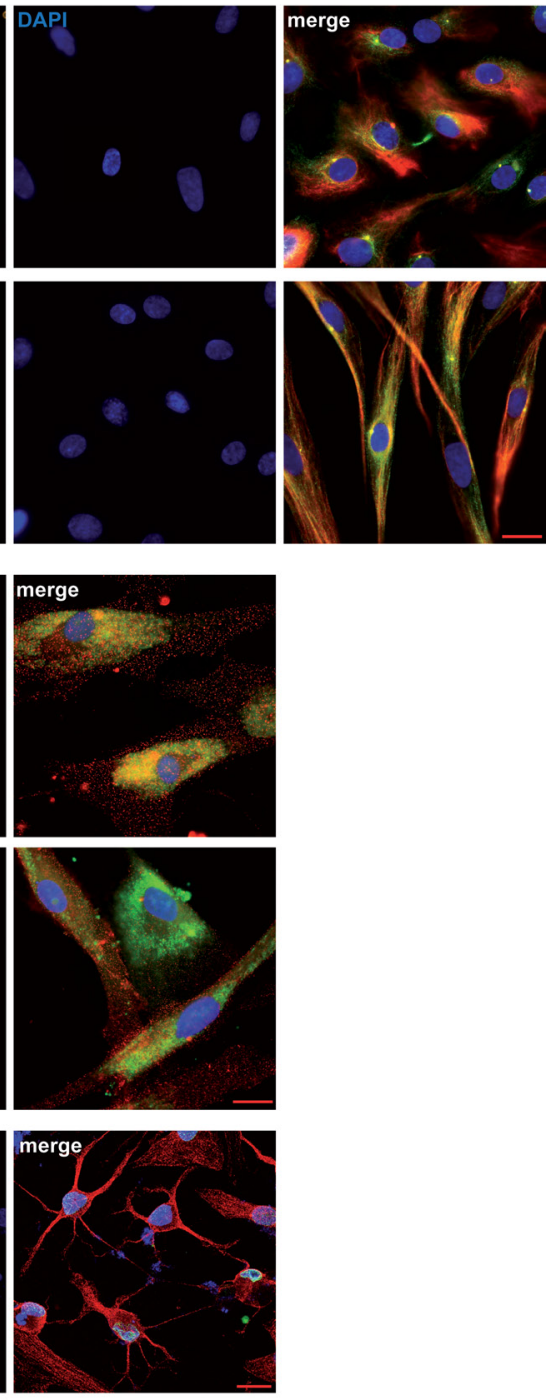

D

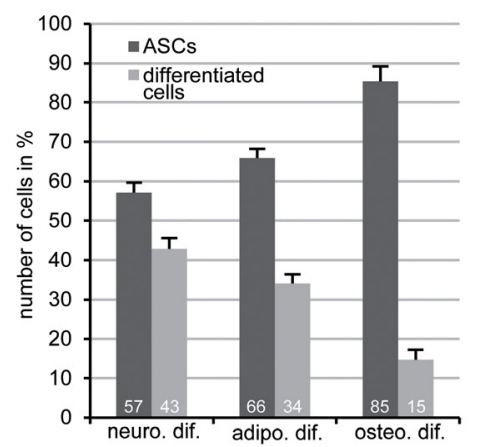

Figure 1: Morphology and differentiation of ASCs isolated from subcutaneous and visceral adipose tissue. A. Immunofluorescence staining. Visceral ASCs (ASCvis) and subcutaneous ASCs (ASCsub) were fixed and stained for $\alpha$-tubulin, vimentin, pericentrin and DNA. Examples are shown. Scale bar: $20 \mu \mathrm{m}$. B. Immunofluorescence staining of cell surface markers in ASCs. Scale bar: $10 \mu \mathrm{m}$. C. Multilineage differentiation capability of ASCs. ASCs were incubated with corresponding differentiation medium for 14 or 21 days. Neuronal differentiation (14 days) was verified with lineage-specific staining of Tuj1 and DCX. Adipogenic differentiation (14 days) was assessed by oil red $\mathrm{O}$ staining displaying lipid vesicle formation. Osteogenic differentiation (21 days) was examined by Alizarin Red $\mathrm{S}$ staining indicating calcium deposits. D. Quantification of the differentiation potential of visceral ASCs by analyzing lineage-specific characteristic marker ( $n=300$ cells for each condition). The results are based on three independent experiments with ASCs obtained from three different donors and presented as mean $\pm \operatorname{SEM}(n=3)$. 
A

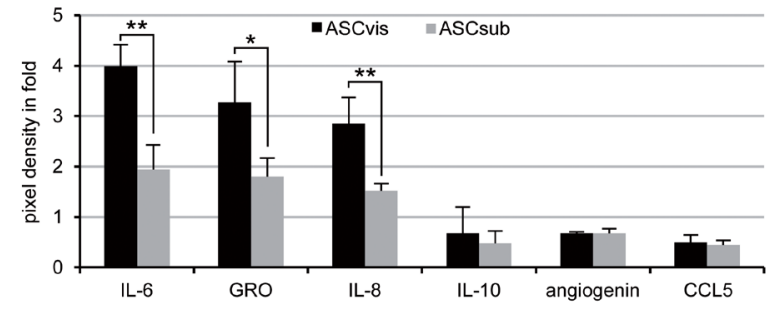

B
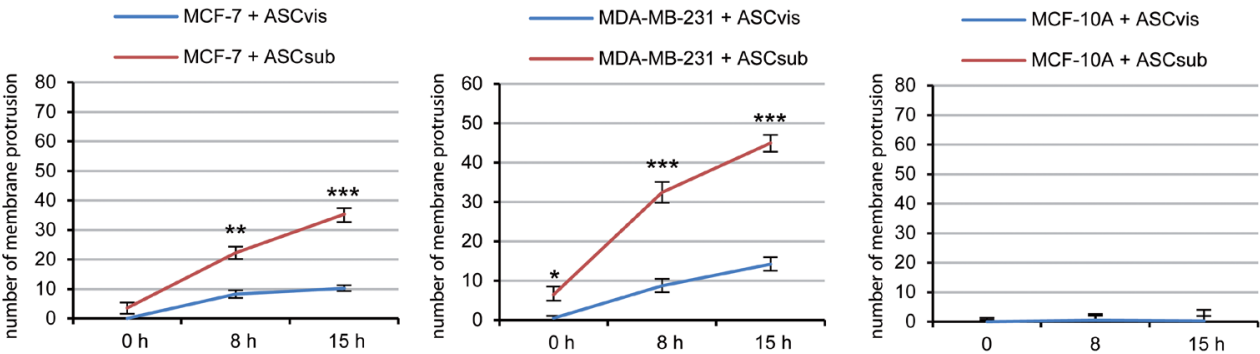

C
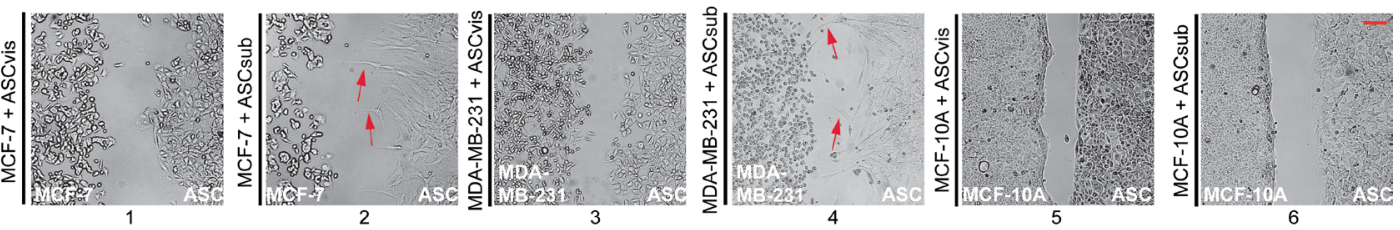

D left side - cancer cells / right side - ASCs
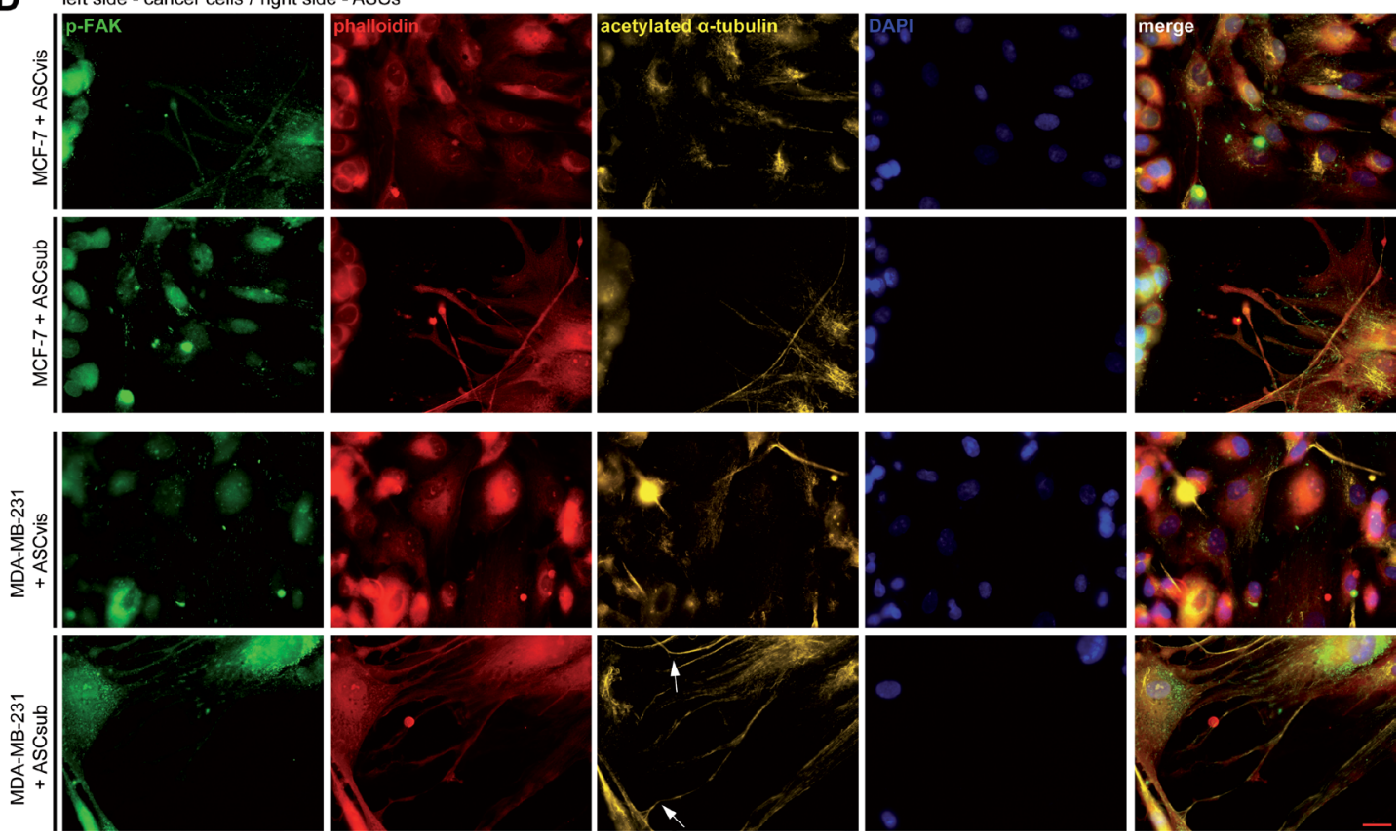

Figure 2: ASCs interact with cancer cells directly and indirectly. A. The cytokine/chemokine array assay. The factors were measured in the supernatants of visceral ASCs (ASCvis) and subcutaneous ASCs (ASCsub) cultured for 3 days by using a human cytokine antibody array. The six most prominent chemokines/chemokines are demonstrated. The results, relative to the positive control provided by the array, are based on three independent experiments with ASCs obtained from three different donors and presented as mean \pm SEM. B. Evaluation of membrane protrusion of ASCs toward MCF-7, MDA-MB-231 and MCF-10A cells. The results are based on three independent experiments with ASCs from three different donors and shown as mean \pm SEM. C. Representatives of ASCs homing to breast cancer cell lines. Red arrows indicate membrane protrusions of ASCs toward breast cancer cells. Normal mammary epithelial MCF-10A cells served as negative control. Scale bar: $250 \mu \mathrm{m}$. D. Immunofluorescence staining of the migration front between ASCs and MCF-7 or MDA-MB-231 cells. Both cell types were stained for p-FAK, phalloidin, acetylated $\alpha$-tubulin and DNA. White arrows depict the connections stabilized by acetylated $\alpha$-tubulin between ASCs and breast cancer cells. Scale bar: $25 \mu \mathrm{m}$. 
Table 3: Cytokines/chemokines/adipokines in the supernatant of ASCs

\begin{tabular}{|c|c|c|c|c|c|}
\hline $\begin{array}{c}\text { ASC-secreted } \\
\text { factors }\end{array}$ & visceral & subcutaneous & $\begin{array}{c}\begin{array}{c}\text { ASC-secreted } \\
\text { factors }\end{array} \\
\end{array}$ & visceral & subcutaneous \\
\hline CCL2 & $0.91 \pm 1.02$ & $0.56 \pm 0.52$ & IL-2 & $0.02 \pm 0.03$ & $0.03 \pm 0.05$ \\
\hline TNF- $\alpha$ & $0.19 \pm 0.15$ & $0.38 \pm 0.38$ & CCL8 & $0.03 \pm 0.04$ & $0.16 \pm 0.23$ \\
\hline IL-3 & $0.20 \pm 0.08$ & $0.29 \pm 0.17$ & IL-4 & $0.01 \pm 0.02$ & $0.02 \pm 0.03$ \\
\hline TNF- $\beta$ & $0.13 \pm 0.04$ & $0.24 \pm 0.19$ & CCL7 & $0.01 \pm 0.02$ & $0.04 \pm 0.05$ \\
\hline CXCL5 & $0.48 \pm 0.37$ & $0.08 \pm 0.12$ & EGF & $0.09 \pm 0.04$ & $0.17 \pm 0.14$ \\
\hline IL-6 & $3.99 \pm 0.43$ & $1.94 \pm 0.49$ & IL-5 & $0.01 \pm 0.02$ & $0.16 \pm 0.11$ \\
\hline angiogenin & $0.68 \pm 0.03$ & $0.68 \pm 0.09$ & IGF-I & $0.03 \pm 0.05$ & $0.02 \pm 0.03$ \\
\hline IL-7 & $0.33 \pm 0.31$ & $0.22 \pm 0.10$ & CCL22 & $0.06 \pm 0.08$ & $0.07 \pm 0.09$ \\
\hline oncostatin $\mathrm{M}$ & $0.31 \pm 0.06$ & $0.35 \pm 0.10$ & CSF1 & $0.22 \pm 0.13$ & $0.04 \pm 0.05$ \\
\hline IL-8 & $2.85 \pm 0.52$ & $1.52 \pm 0.14$ & CXCL9 & $0.02 \pm 0.03$ & $0.02 \pm 0.03$ \\
\hline GRO & $3.27 \pm 0.81$ & $1.80 \pm 0.37$ & GM-CSF & $0.03 \pm 0.05$ & $0.06 \pm 0.08$ \\
\hline IL-10 & $0.68 \pm 0.52$ & $0.48 \pm 0.24$ & CCL15 & $0.03 \pm 0.05$ & $0.20 \pm 0.14$ \\
\hline CCL5 & $0.49 \pm 0.16$ & $0.45 \pm 0.09$ & thrombopoietin & $0.02 \pm 0.02$ & $0.03 \pm 0.04$ \\
\hline GRO- $\alpha$ & $0.38 \pm 0.35$ & $0.06 \pm 0.08$ & VEGF & $0.02 \pm 0.03$ & $0.03 \pm 0.05$ \\
\hline SDF-1 & $0.13 \pm 0.07$ & $0.12 \pm 0.04$ & IL-12 & $0.03 \pm 0.04$ & $0.03 \pm 0.05$ \\
\hline IL-1 $\alpha$ & $0.12 \pm 0.06$ & $0.59 \pm 0.69$ & SCF & $0.03 \pm 0.04$ & $0.04 \pm 0.06$ \\
\hline CCL17 & $0.14 \pm 0.04$ & $0.26 \pm 0.21$ & PDGFB & $0.02 \pm 0.03$ & $0.02 \pm 0.03$ \\
\hline IL-1 $\beta$ & $0.13 \pm 0.08$ & $0.56 \pm 0.68$ & CCL1 & $0.01 \pm 0.02$ & $0.02 \pm 0.03$ \\
\hline INF- $\gamma$ & $0.12 \pm 0.12$ & $0.30 \pm 0.34$ & IL-13 & $0.01 \pm 0.02$ & $0.02 \pm 0.03$ \\
\hline TGF- $\beta 1$ & $0.12 \pm 0.08$ & $0.21 \pm 0.19$ & leptin & $0.04 \pm 0.05$ & $0.03 \pm 0.05$ \\
\hline IL-15 & $0.02 \pm 0.02$ & $0.02 \pm 0.03$ & & & \\
\hline
\end{tabular}

Relative chemokine secretion ratio of ASCs. The signal of the positive control was assigned as 1.

Abbreviations: CCL, C-C motif chemokine; TNF, tumor necrosis factor; IL, interleukin; CXCL, C-X-C motif chemokine; GRO, growth-regulated protein; SDF, stromal cell-derived factor 1; TGF, transforming growth factor; EGF, epidermal growth factor; IGF, insulin-like growth factor; CSF, colony-stimulating factor; GM-CSF, granulocyte-macrophage colony-stimulating factor; VEGF, vascular endothelial growth factor; SCF, stem cell factor; PDGF, platelet-derived growth factor.

ASCs was measured at indicated time points. Compared to normal mammary epithelial cells MCF-10A (Figure 3A), low malignant breast cancer cells MCF-7 expanded significantly faster in the presence of either visceral or subcutaneous ASCs (Figure 3B). By contrast, visceral ASCs affected hardly and subcutaneous ASCs even inhibited proliferation of the highly metastatic breast cancer cells MDA-MB-231 (Figure 3C). The stimulatory effect of ASCs on MCF-7 was further underscored by an increase in the mitotic marker phosphorylated histone $\mathrm{H} 3$ (pHH3, S10) after five days of direct co-culture with visceral or subcutaneous ASCs (Figure 3D). To further underscore these data, Ruby-H2B labelled MCF-7 cells and EGFP-H2B marked MDA-MB-231 cells were directly co-cultured with ASCs for up to five days and the viability of the fluorescent cells were evaluated by flow cytometry. Compared to control Ruby-H2B MCF-7 cells, the cell number of co-cultured Ruby-H2B MCF-7 with visceral ASCs and subcutaneous ASCs was increased by $30 \%$ and 13\%, respectively (Figure 3E). Again, proliferation of EGFP-H2B MDA-MB-231 cells was even slightly reduced in the presence of visceral or subcutaneous ASCs (Figure S2D). These different outcomes between MCF-7 and MDA-MB-231 cells might be ascribed to their individual proliferation pattern associated with their receptor composition: MDA-MB-231 cells proliferate autonomously representing a highly invasive cell type with a triple negative composition for estrogen receptor (ER), progesterone receptor (PR) and human epidermal growth factor receptor 2 (HER2), whereas less malignant MCF-7 cells, resistant to apoptosis due to the lack of caspase-3, proliferate upon stimulation with expression for all ER, PR and HER2 [16].

To study the impact of the direct co-culturing on the mRNA expression, total RNA was isolated from cocultured and sorted Ruby-H2B MCF-7 cells and 12 genes related to the cell cycle were analyzed. Five of them were increased compared to that in control Ruby-H2B MCF7 cells (Figure 3F) whereas the remaining 7 genes p21, NANOG, p53, RAC1, SOX2, HIF1 $\alpha$, MMP9, Aurora A 
and cyclin B1 were hardly affected (data not shown). The mRNA of Aurora B and Polo-like kinase 1 (Plk1), two important mitotic genes, increased slightly in Ruby-H2B MCF-7 cells co-cultured with visceral ASCs (Figure 3F).
More interestingly, the mRNA expression level of the transcription suppressor B-cell lymphoma 6 (BCL6) and cytokines IL-6 and IL-8 were highly increased (Figure $3 \mathrm{~F})$. All three are known to be involved in multiple cellular
A

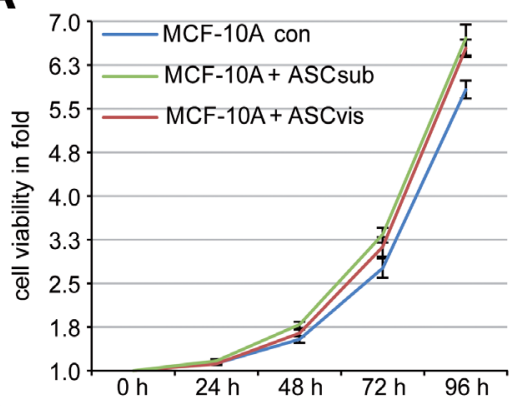

B

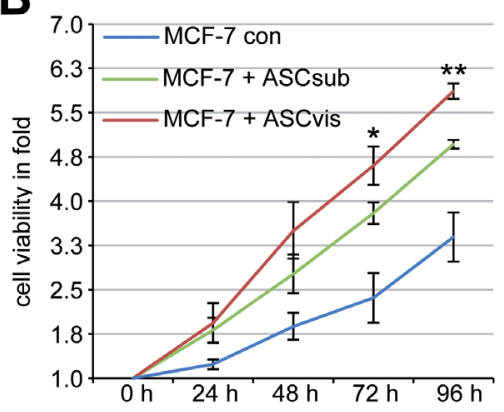

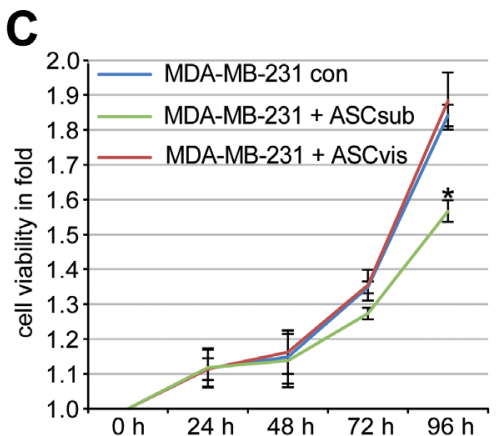
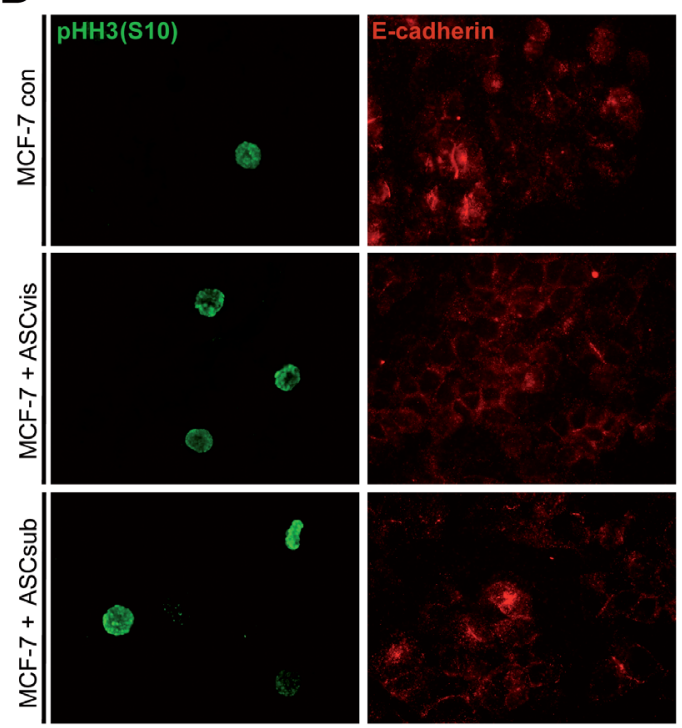

E

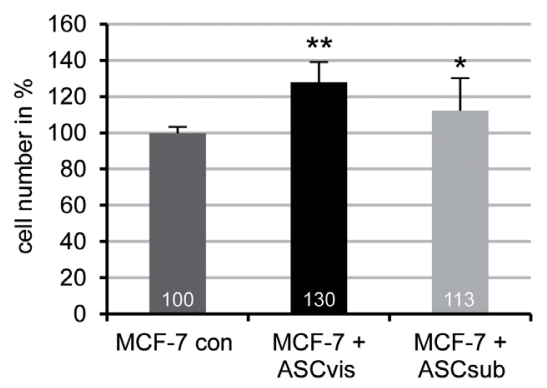

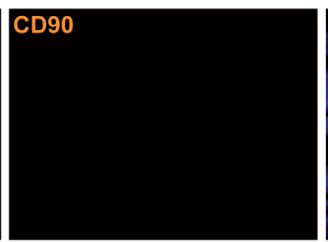
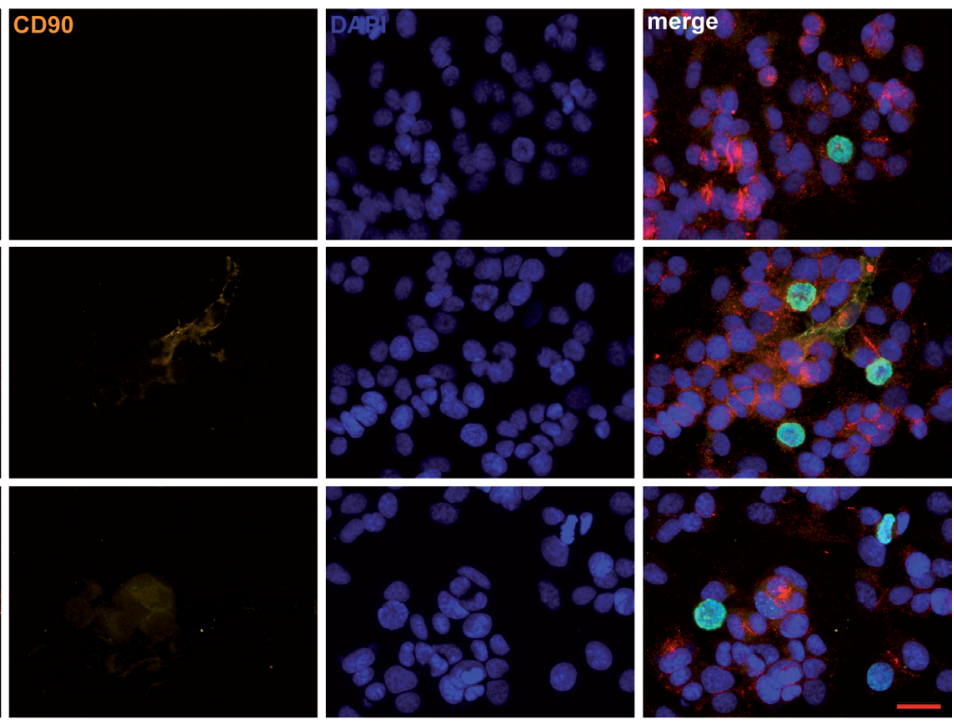

$\mathbf{F}$

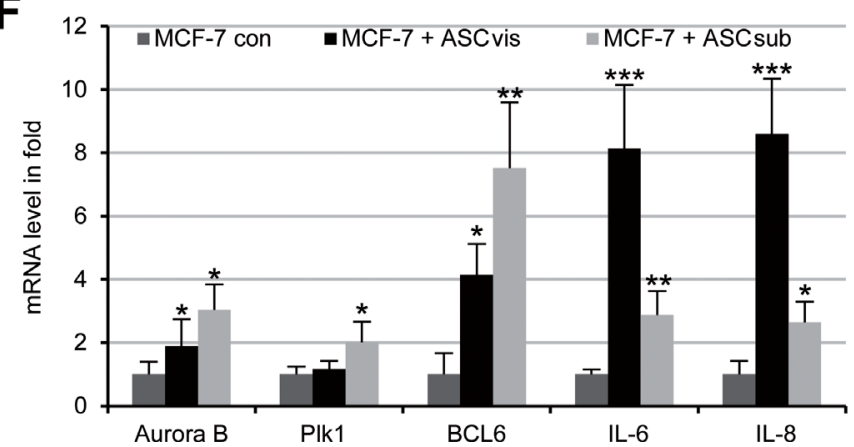

Figure 3: MCF-7 cells proliferate strongly upon direct co-culturing with ASCs, associated with increased mRNA expression of BCL6, IL-6 and IL-8. A.-C. Cell viability assay. MCF-10A A., MCF-7 B. and MDA-MB-231 C., in the presence or absence of $20 \%$ subcutaneous ASCs (ASCsub) or visceral ASCs (ASCvis), were seeded in 96-well plates. Cell viability was measured via CellTiter-Blue ${ }^{\circledR}$ assay. The results are based on three independent experiments with ASCs from three different donors and presented as mean \pm SEM. $* p<0.05,{ }^{* *} p<0.01$. D. MCF-7 cells incubated with ASCs for $96 \mathrm{~h}$ were stained for phospho-histone $\mathrm{H} 3$ ( $\mathrm{pHH} 3, \mathrm{~S} 10$ ), a mitotic marker, E-cadherin, CD90 as ASC marker and DNA. Non-treated MCF-7 cells were taken as control. Representatives are shown. Scale bar: $25 \mu \mathrm{m}$. E. Cell number of Ruby-H2B MCF-7 cells co-cultured with $20 \%$ visceral ASCs or subcutaneous ASCs, evaluated by flow cytometry. The results are based on three independent experiments with ASCs from three different donors and shown as from three different donors and shown as mean $\pm \operatorname{SEM}(n=3) .{ }^{*} p<0.05,{ }^{* *} p<0.01$. F. The gene expression of Ruby-H2B MCF-7 cells cultured alone or co-cultured with ASCs. The results are presented as mean $\pm \mathrm{SD}$ and the values represent absolute mRNA levels relative to the standard curve. ${ }^{*} p<0.05,{ }^{* *} p<0.01,{ }^{* * *} p<0.001$. 
processes like cell cycle regulation, proliferation, tumor initiation and progression [17-19].

\section{ASCs induce the epithelial-to-mesenchymal transition by indirect co-culturing}

To address if ASCs could also indirectly influence cancer cells, an indirect co-culture experiment was performed in a transwell system. Breast cancer cells and ASCs were seeded in individual chambers of a transwell system for up to 14 days, where they had no direct cellcell contact but they were able to exchange their media and secreted factors. The morphology of MCF-7 cells was visualized at indicated time points and the first spindlelike cell shape was observed after 4 days of indirect co-culturing (Figure S3A). During 14 days of indirect co-culture most MCF-7 cells lost their characteristic epithelial morphology with apical-basal polarity and gained a mesenchymal phenotype with spindle-shaped morphology (Figure S3A, day 7 to day 14), a process referred to as the epithelial-to-mesenchymal transition (EMT). To test if EMT is reversible, mesenchymal-like MCF-7 cells were then cultured alone without ASCs and the cell morphology was monitored at indicated time points. Interestingly, a timely decrease in mesenchymallike and an increase in epithelial-like MCF-7 cells were observed (Figure S3B). To underscore this observation, cells were stained for confocal microscopy. Indeed, the analysis revealed a membrane and cytoplasmic distributed expression of N-cadherin and vimentin in MCF-7 cells co-cultured with visceral ASCs for 14 days (Figure 4A, $3^{\text {rd }}$ and $4^{\text {th }}$ panel). E-cadherin was still detectable above the background levels in these cells, but disappeared from the plasma membrane with a diffuse distribution in the cytoplasm (Figure $4 \mathrm{~A}, 3^{\text {rd }}$ and $4^{\text {th }}$ panel). A similar morphologic change and expression of vimentin and E-cadherin were also observed in MCF-10A cells after incubation with visceral ASCs (Figure S3C). In contrast, MCF-7 control cells as well as MCF-7 cells co-cultured with subcutaneous ASCs for 14 days still displayed a strong expression of E-cadherin at the membrane and in the cytoplasm, with nearly no detectable $\mathrm{N}$-cadherin and vimentin (Figure $4 \mathrm{~A}, 1^{\text {st }}$ and $2^{\text {nd }}$ panel and $5^{\text {th }}$ and $6^{\text {th }}$ panel). To further corroborate these results, cells were harvested at indicated time points for Western blot analysis. MCF-7 cells indirectly co-cultured with visceral ASCs were demonstrative for mesenchymal cell markers, with high expression levels of fibronectin, $\mathrm{N}$-cadherin and vimentin (Figure $4 \mathrm{~B}, 1^{\text {st }}$ and $2^{\text {nd }}$ row, and $4^{\text {th }}$ row, lane 3 ), as observed in ASCs (Figure 4B, $1^{\text {st }}$ and $2^{\text {nd }}$ row, and $4^{\text {th }}$ row, lane 6 and 7), and with losing E-cadherin (Figure 4B, $3^{\text {rd }}$ row, lane 3 ). Also the reversibility of this process could be observed in mesenchymal-like MCF-7 cells cultured alone for 14 and 21 days, with a decrease in fibronectin and $\mathrm{N}$-cadherin and an increase in E-cadherin (Figure 4B, $1^{\text {st }}$ to $3^{\text {rd }}$ row, lane 4 and 5), comparable to MCF-7 control cells (Figure $4 \mathrm{~B}, 1^{\text {st }}$ to $3^{\text {rd }}$ row, lane 2).

Nevertheless, subcutaneous ASCs were able to induce EMT in MCF-7 after 21 days of indirect coculture, displayed by a changed morphology, increased vimentin and decreased E-cadherin expression (Figure S3D). The observation, subcutaneous ASCs induced EMT with a significantly decreased rate and a longer time period in MCF-7 cells (Figure S3E), might be explained by reduced secretion of the most detected cytokines from subcutaneous ASCs compared to visceral ASCs (Figure 2A).

It is well known that EMT reduces very often cell proliferation [20-22]. To functionally corroborate the EMT phenotype induced by ASCs, we performed cell viability assays. MCF-7 control cells and MCF-7 cells indirectly co-cultured with ASCs for 14 days were seeded into a 96-well plate for up to $96 \mathrm{~h}$. While MCF7 cells indirectly co-cultured with visceral ASCs showed a reduced proliferation rate of $33.5 \%$, MCF-7 indirectly incubated with subcutaneous ASCs displayed a reduction of $16.2 \%$ at $96 \mathrm{~h}$ compared to MCF-7 control cells (Figure 4C). Collectively, the data imply that the indirect coculture with ASCs induces EMT in MCF-7 cells and this transition is reversible associated with significant changes in their cytoskeleton composition, morphological changes and a reduced cell proliferation.

\section{The induced EMT is triggered by multiple signaling cascades in MCF-7 cells}

Numerous cytokines and chemokines have been reported to be involved in the EMT process of cancer cells via multiple signaling pathways [23]. To address this issue, we measured at first the mRNA levels of several cytokine genes in MCF-7 cells after co-culture with visceral ASCs. The gene expression is demonstrated by $\Delta \mathrm{Ct}$ value, which is reversely related to the amount of target mRNA. Interestingly, co-cultured MCF-7 cells showed a remarkable upregulation of IL-6, IL-8 and IL10 mRNA compared to MCF-7 control cells (Figure 5A). The cyclin B1 mRNA level was slightly reduced in the ASC co-cultured MCF-7 cells reflecting the reduced cell proliferation of EMT cells (Figure 5A). Of note, the gene expression of the transcription suppressor BCL6 was also increased (Figure 5A). To look closely at EMT, we performed further Western blot analysis with lysates from control MCF-7 cells, ASC co-cultured MCF-7 cells and MCF-7 cells exposed to hypoxia $\left(2 \% \mathrm{O}_{2}\right)$, the late was taken as an EMT positive control. Interestingly, compared to control MCF-7 cells, visceral ASC co-cultured MCF-7 cells displayed an increase in transcription factors Snail, Slug and STAT3 associated with enhanced IL-6 (Figure 5B and 5C). Moreover, an activation of the phospho-AKT (p-AKT), p-ERK1/2 and p-FAK was also observed (Figure 
A
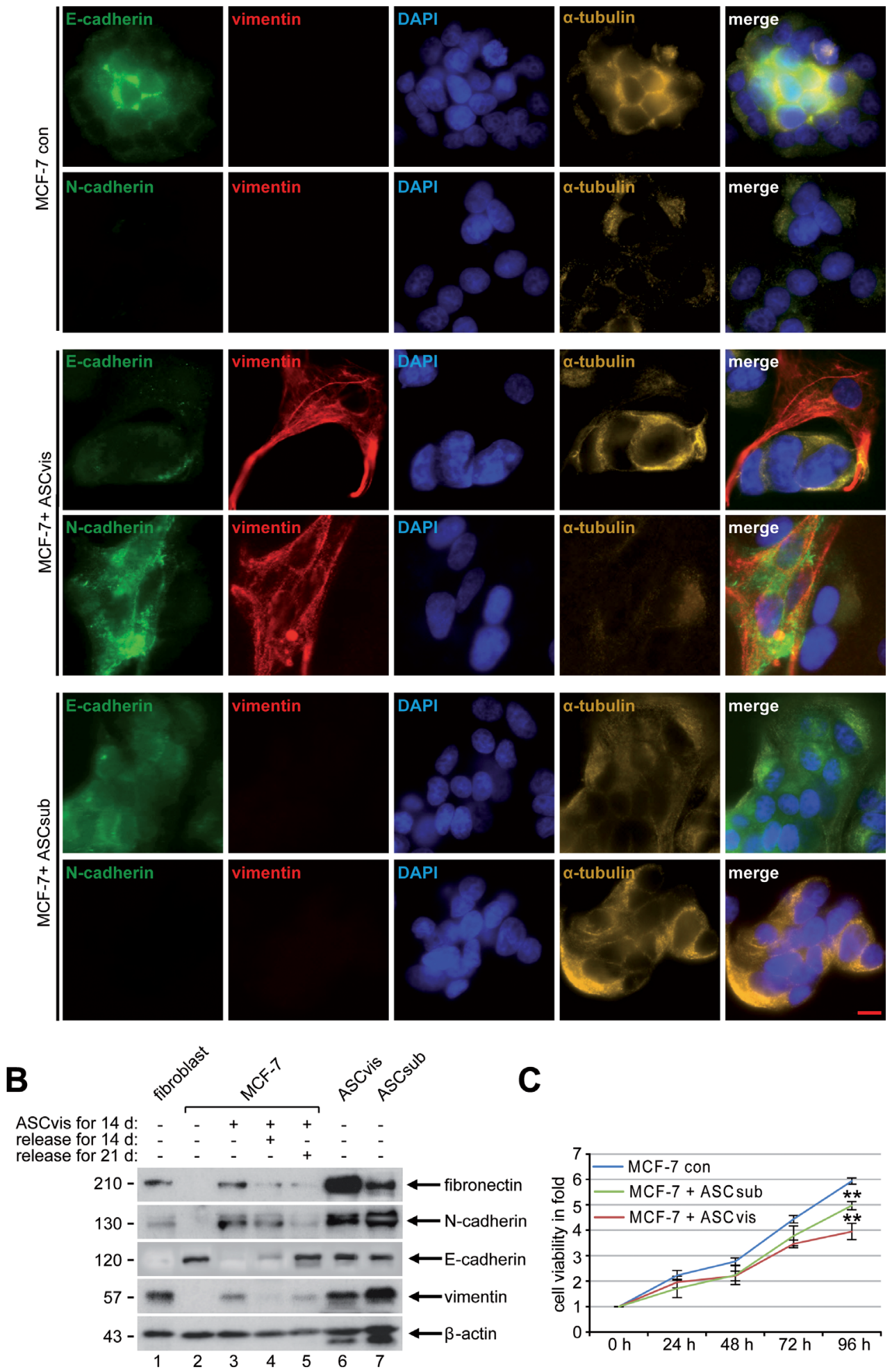

Figure 4: Indirect co-culturing with ASCs results in EMT in MCF-7 cells. A. Immunofluorescence staining. MCF-7 cells were stained for the epithelial marker E-cadherin, the mesenchymal markers vimentin and $\mathrm{N}$-cadherin, DNA and $\alpha$-tubulin after 14 days of indirect co-culture with visceral ASCs. Representatives are depicted. Scale bar: $25 \mu \mathrm{m}$. B. Western blot analysis. Cellular lysates were prepared from MCF-7 cells, non-treated as control (con), indirectly co-cultivated with visceral ASCs (ASCvis) for 14 days, and co-cultured MCF-7 cells released for 14 and 21 days afterwards. Lysates from untreated fibroblasts, visceral ASCs or subcutaneous ASCs were taken as positive control cells. $\beta$-actin served as loading control. C. Cell viability assay. MCF-7 cells indirectly co-cultured with ASCs were seeded in 96-well plates and their viability was evaluated via a CellTiter-Blue ${ }^{\circledR}$ assay. The results are based on three independent experiments with ASCs obtained from three different donors and presented as mean \pm SEM. MCF-7 cells without co-culture served as control (con). 
A
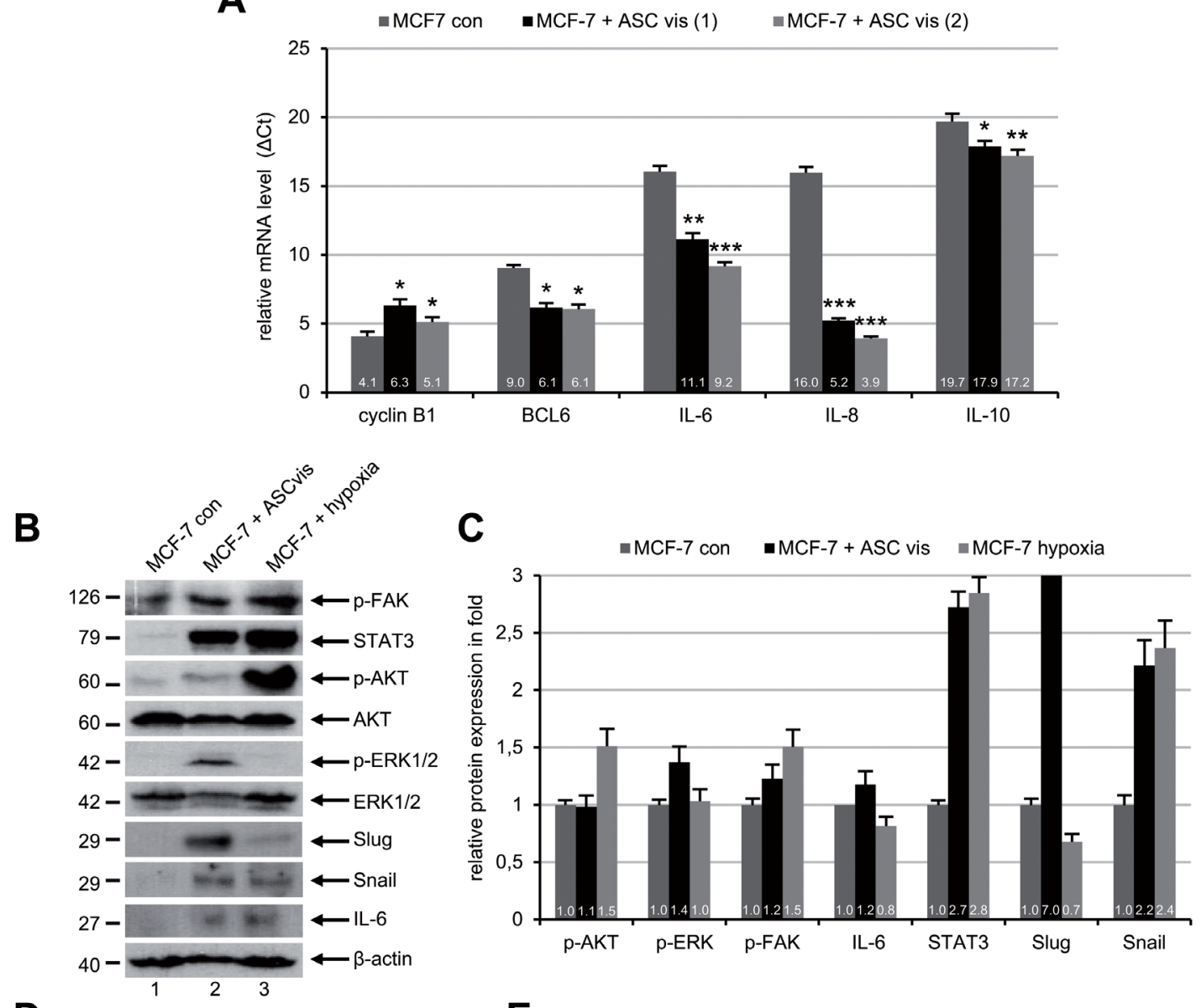

D

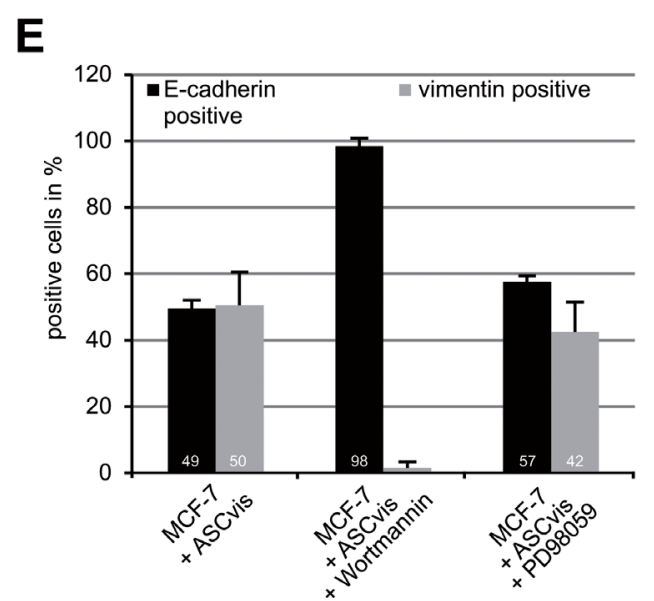

Figure 5: ASCs induce EMT in MCF-7 cells through multiple signaling pathways. A. The mRNA expression levels of the mitotic marker cyclin B1, transcription suppressor BCL6 and cytokines IL-6, IL-8 and IL-10 were determined by real-time PCR in MCF-7 cells cultured alone or in co-culture with visceral ASCs (ASCvis) from two donors. The results are presented as mean \pm SD. $* p<0.05$, ${ }^{* *} p<0.01, * * * p<0.001$. Note: each gene expression is demonstrated by $\Delta \mathrm{Ct}$ value, which is normalized to endogenous GAPDH and is reversely related to the amount of target mRNA. B. Western blot analyses with indicated antibodies. Cellular lysates were prepared from MCF-7 control cells and MCF-7 cells indirectly co-cultured with visceral ASCs for 14 days. Lysates from MCF-7 cells exposed to hypoxia $\left(2 \% \mathrm{O}_{2}\right)$ were taken as positive mesenchymal control. $\beta$-actin served as loading control. C. Quantification of Western blot analyses in B., relative to corresponding $\beta$-actin signal. The results are based on two independent experiments and presented as mean \pm SEM. The value in MCF-7 control cells is defined as 1 fold. The quantification was performed with ImageJ. D. MCF-7 cells were cultured alone or with visceral ASCs in the presence of a PI3K inhibitor Wortmannin $(50 \mathrm{nM})$ or a MAPK inhibitor PD98059 (10 $\mu \mathrm{M})$. After 20 days cellular lysates were prepared for Western blot analyses with indicated antibodies. $\beta$-actin served as loading control. E. The treated cells in D. were fixed and stained for the epithelial marker E-cadherin and mesenchymal marker vimentin. Positive cells were counted $(n=200$ cells for each condition) and the results are presented as mean $\pm \operatorname{SD}(n=3)$. 
$5 \mathrm{~B}$ and $5 \mathrm{C})$.

To further elucidate which of these pathways is important for the induction of EMT, MCF-7 cells were co-cultured with visceral ASCs for 20 days in the presence of low concentrations of Wortmannin $(50 \mathrm{nM})$, a potent phosphatidylinositol 3-kinase (PI3K) inhibitor [24], or PD98059 $(25 \mu \mathrm{M})$ inhibiting the mitogen-activated protein

A

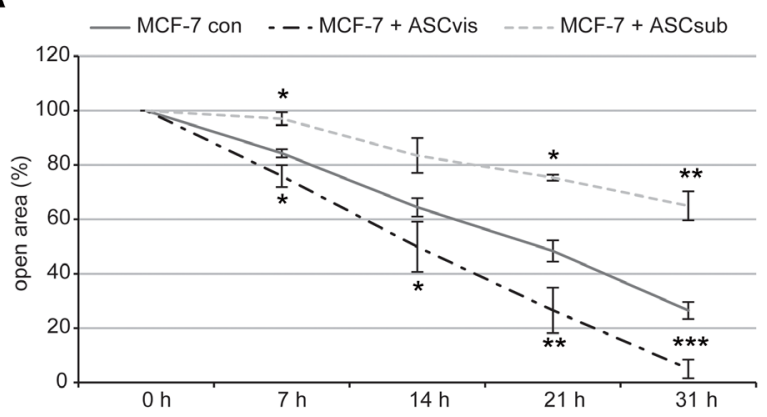

C

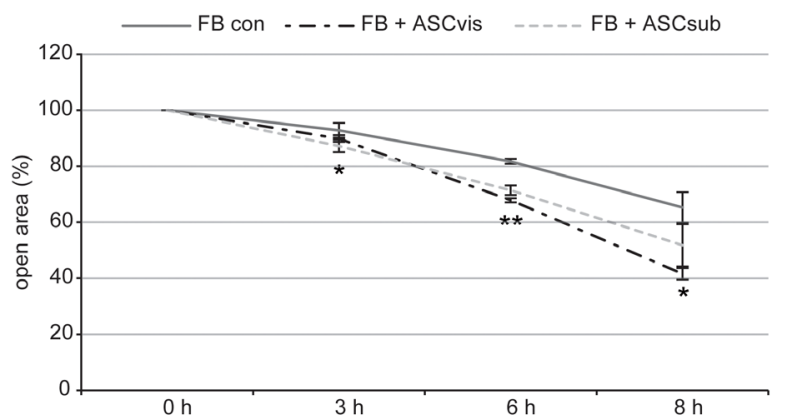

$\mathbf{E}$

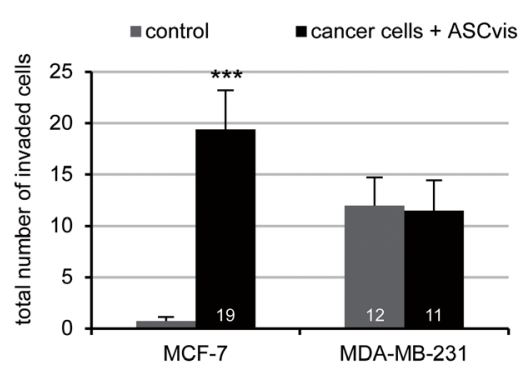

$\mathbf{F}$
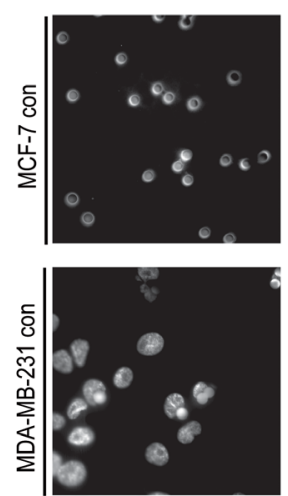

kinase (MAPK) family [25]. Wortmannin blocked the EMT induction in MCF-7 co-cultured with visceral ASCs by displaying no increase in the expression of vimentin, p-AKT and p-STAT3 compared to MCF-7 control cells (Figure 5D, lane 1 and 3), indicating the activation of PI3K pathway is essential for the EMT process. On the other hand, the inhibition of the MAPK pathway with
B

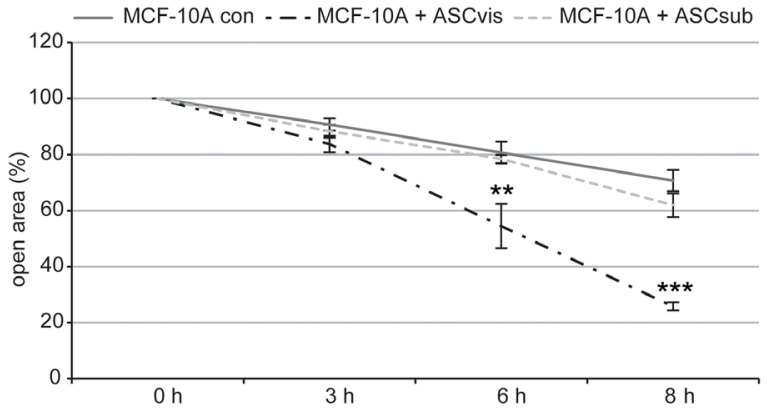

D

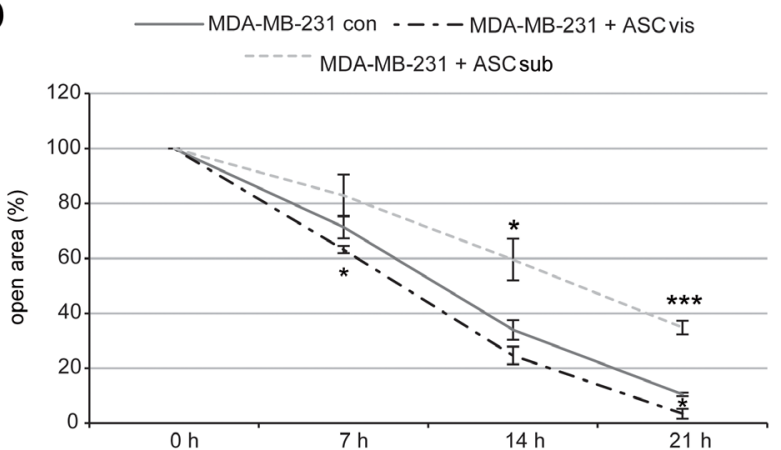

G

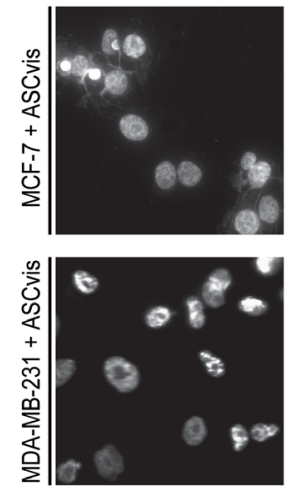

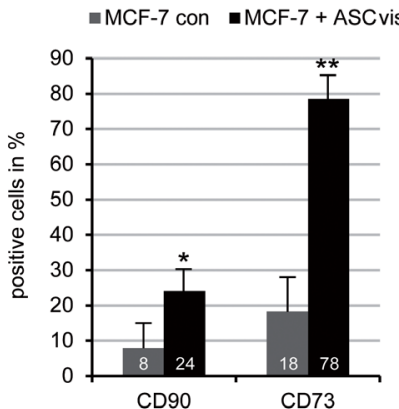

Figure 6: ASCs increase malignant properties of breast cancer cells. Wound healing/migration assay was performed with MCF7, MCF-10A, MDA-MB-231 and fibroblasts in the presence or absence of visceral ASCs (ASCvis) or subcutaneous ASCs (ASCsub) and pictures were taken at indicated time points to document the migration front. A.-D. Quantification of the open area between both migration fronts at various time points in MCF-7 A., MCF-10A B., fibroblast (FB) C. and MDA-MB-231 cells D., using the AxioVision SE64 Rel. 4.9 software $\left(n=5\right.$ visual fields of $1350 \times 1800 \mu \mathrm{m}^{2}$ for each condition). The cell-free area of each individual condition at $0 \mathrm{~h}$ was assigned as $100 \%$. The results are based on three independent experiments with ASCs from three different donors and presented as mean \pm SEM. ${ }^{*} p<0.05,{ }^{* *} p<0.01,{ }^{* * *} p<0.001$. E. Invasion assay via a transwell system. Quantification of invaded MCF-7 and MDA-MB-231 cells cultured alone or co-cultured with visceral ASCs. The number of invaded breast cancer cells cultured alone was assigned as 1 fold. The results are presented as mean $\pm \operatorname{SEM}\left(n=5\right.$ visual fields of $170 \times 225 \mu \mathrm{m}^{2}$ for each condition). $* * * p<0.001$. F. Representatives of invaded MCF-7 and MDA-MB-231 cells cultured alone or indirectly cultured with visceral ASCs for 14 days. Scale bar: $20 \mu \mathrm{m}$. G. MCF-7 cells cultured alone or co-cultured with visceral ASCs for 14 days were fixed and stained for mesenchymal stem cell surface markers CD73 and CD90. Positive cells were evaluated by flow cytometry. The results are obtained from three independent experiments with ASCs from three different donors and presented as mean \pm SEM. * $p<0.05 ; * p<0.01$. 
PD98059 hardly affected the EMT induction evidenced by increased vimentin, p-AKT and p-STAT3, and decreased E-cadherin (Figure 5D, lane 2 and 4). To corroborate these results, immunofluorescence staining was carried out. While $51 \%$ of visceral ASCs co-cultured with MCF-7 cells were positive for the mesenchymal marker vimentin, only few of these cells expressed vimentin in the presence of Wortmannin (Figure 5E). Again, the MAPK inhibitor PD98059 was not able to affect the EMT process in MCF7 cells co-cultured with visceral ASCs showing increased vimentin expression (Figure 5E). These data provide evidence that EMT of MCF-7 cells induced by ASCs is mediated by multiple pathways, yet predominantly by the PI3K pathway known to be activated by IL-6 and IL-8 [23], which are highly secreted by ASCs (Figure 2A).

\section{Indirect co-culture with ASCs promotes malignancy of breast cancer cells}

We were then interested in the invasive property of breast cancer cells co-cultured with ASCs. A woundhealing/migration assay was performed with different cell lines indirectly co-cultured with ASCs. After co-culturing with visceral ASCs, breast cancer cells MCF-7 and MDAMB-231, together with normal mammary epithelia cells MCF-10A and fibroblasts, displayed a significantly increased wound healing capacity compared to control cells (Figure 6A-6D and Figure S4A-S4D). In the context of co-culturing with subcutaneous ASCs, intriguingly, non-tumorigenic cell lines like MCF-10A and fibroblasts showed a slightly increased wound healing capacity, whereas tumorigenic MCF-7 cells and metastatic MDAMB-231 cells exhibited a slower migration rate compared to control cells (Figure 6A-6D and Figure S2A-S2D). To examine the invasive feature of breast cancer cells, ASC co-cultured cells were used for a well-established invasion assay [26]. As expected, MCF-7 control cells were not able to invade the matrigel layer of the invasion chamber, whereas MCF-7 co-cultured with visceral ASCs displayed a highly significant increase in the number of invading cells (Figure 6E and 6F). Intriguingly, visceral ASCs stimulated hardly the invasive capability of MDA-MB-231 cells, which are already highly invasive metastatic breast cancer cells (Figure 6E and 6F). Thus, the data imply that ASCs promote cell migration of different cell lines and facilitates the invasion mainly in non/less invasive breast cancer lines such as MCF-7.

The recently emerged concept of cancer stem cells as a cell state not as a cell type [27] led to the question, if the indirect co-culture with ASCs is sufficient to induce the expression of mesenchymal stem cell markers in MCF-7 cells. To answer this question, visceral ASC cocultured MCF-7 cells were measured by flow cytometry for mesenchymal stem cell markers CD90 and CD73, which have been shown to be correlated with tumor growth, metastasis and drug resistance in breast cancer cells [28, 29]. Indeed, the number of CD90 and CD73 positive stained MCF-7 cells was increased by $16 \%$ and $60 \%$, respectively, after co-culture with visceral ASCs, compared to MCF-7 control cells (Figure 6G). These results further support the notion that ASCs could change relatively differentiated $\mathrm{MCF}-7$ into more progenitor state conferring the malignant properties.

\section{ASC signaling confers resistance to Plk1 inhibitors in MCF-7 cells}

EMT is linked to drug resistance and poor prognosis for patients [30]. Plk1 is one of the most promising targets for molecular cancer treatment and its inhibitors block efficiently proliferation of various cancer cells including MDA-MB-231 and MCF-7 cells [31, 32]. We wondered if the EMT induction renders MCF-7 resistant to Plk1 inhibitors. MCF-7 cells, mesenchymal-like MCF-7 cells induced by co-culturing with visceral ASCs, and visceral ASCs were subjected to Plk1 inhibitors BI 2536, BI 6727 and Poloxin, and the cell viability and the mitotic index were examined. Compared to control MCF-7 cells (Figure 7A), mesenchymal-like MCF-7 cells were obviously resistant to BI 2536 and BI 6727 by showing no significant proliferative inhibition (Figure 7B). Interestingly, Poloxin, an inhibitor targeting the polo-box binding domain of Plk1, displayed an inhibitory effect on those cells (Figure 7B), which requires further investigation. As expected, visceral ASCs responded hardly to Plk1 inhibitors (Figure 7C). Treated cells were further stained for mesenchymal marker vimentin and the mitotic marker pHH3 (S10) for microscopy. Compared to control MCF-7 cells (Figure 7D, upper panel), the pHH3 (S10) positive cells were clearly reduced in ASC co-cultured MCF-7 cells (Figure 7D, lower panel), which were vimentin positive (Figure 7D, lower panel) indicating their mesenchymal-like phenotype. Further evaluation corroborated a strong reduction of the pHH3(S10) staining in mesenchymal-like MCF-7 cells upon BI compound treatment (Figure 7E). These results point to the notion that MCF-7 cells co-cultured with ASCs acquire resistance to Plk1 inhibitors BI 2536 and BI 6727 , likely obtained by the changed cytoskeleton composition and decreased proliferation rate [23].

\section{DISCUSSION}

The tumor microenvironment plays a crucial role in cancer development and progression [33]. To ensure the safety usage of ASCs in new regenerative therapy, it is fundamental to understand the molecular interactions between ASCs and cancer cells. A great body of work has been done, which has shed light on this issue and also raised the safety concerns [8-10, 34-38]. In the current study, we have isolated ASCs from subcutaneous 
and visceral adipose tissues of the same donor and systematically characterized the features of these paired ASCs and addressed their impact on breast cancer cells.

We show that both subcutaneous and visceral ASCs express the cell surface markers characteristic of the mesenchymal stem cells. They display however distinct cell morphology in culture, at least in the early passages: ASCs from subcutaneous adipose tissues incline to be fibroblastic-like, whereas their counterparts from visceral adipose tissues tend to be "epithelial"-like. Moreover, visceral ASCs are more competent of secreting soluble factors, differentiating into other cell types and impact more strongly on other cells, whereas subcutaneous ASCs are more capable of homing toward breast cancer cells. The differences between subcutaneous ASCs and visceral ASCs could be ascribed to their different original sources [39] and varied surroundings. In particular, the surrounded adipocytes, namely the adipocytes in subcutaneous
A

B
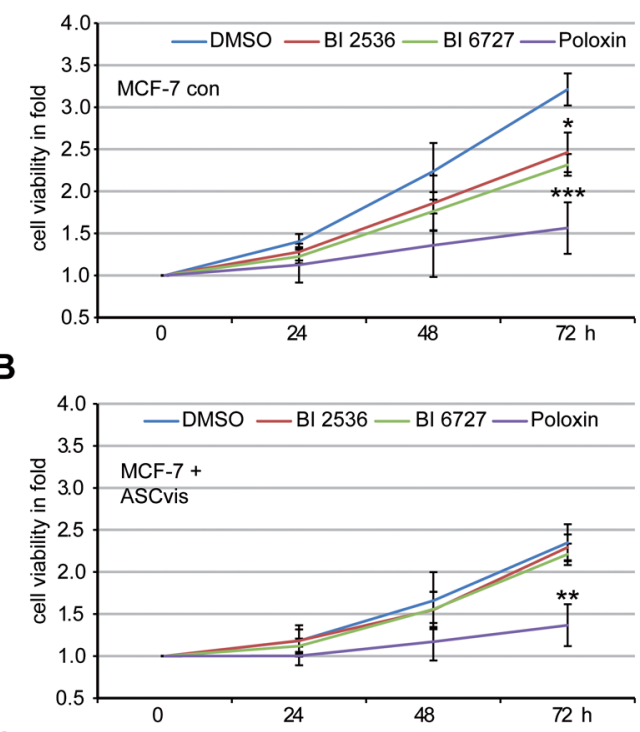

C

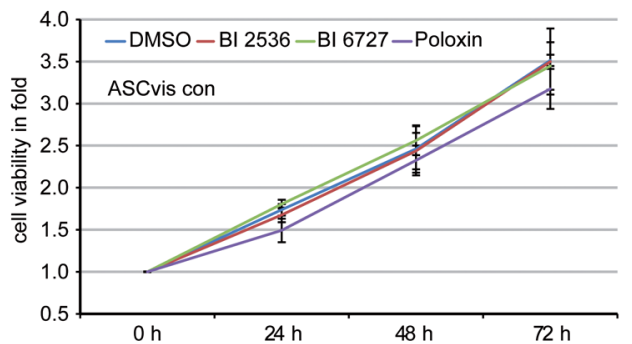

E

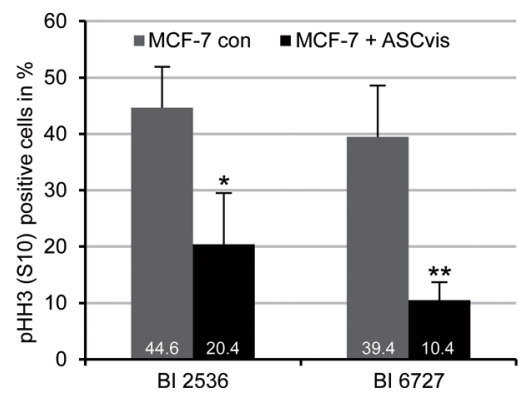

D
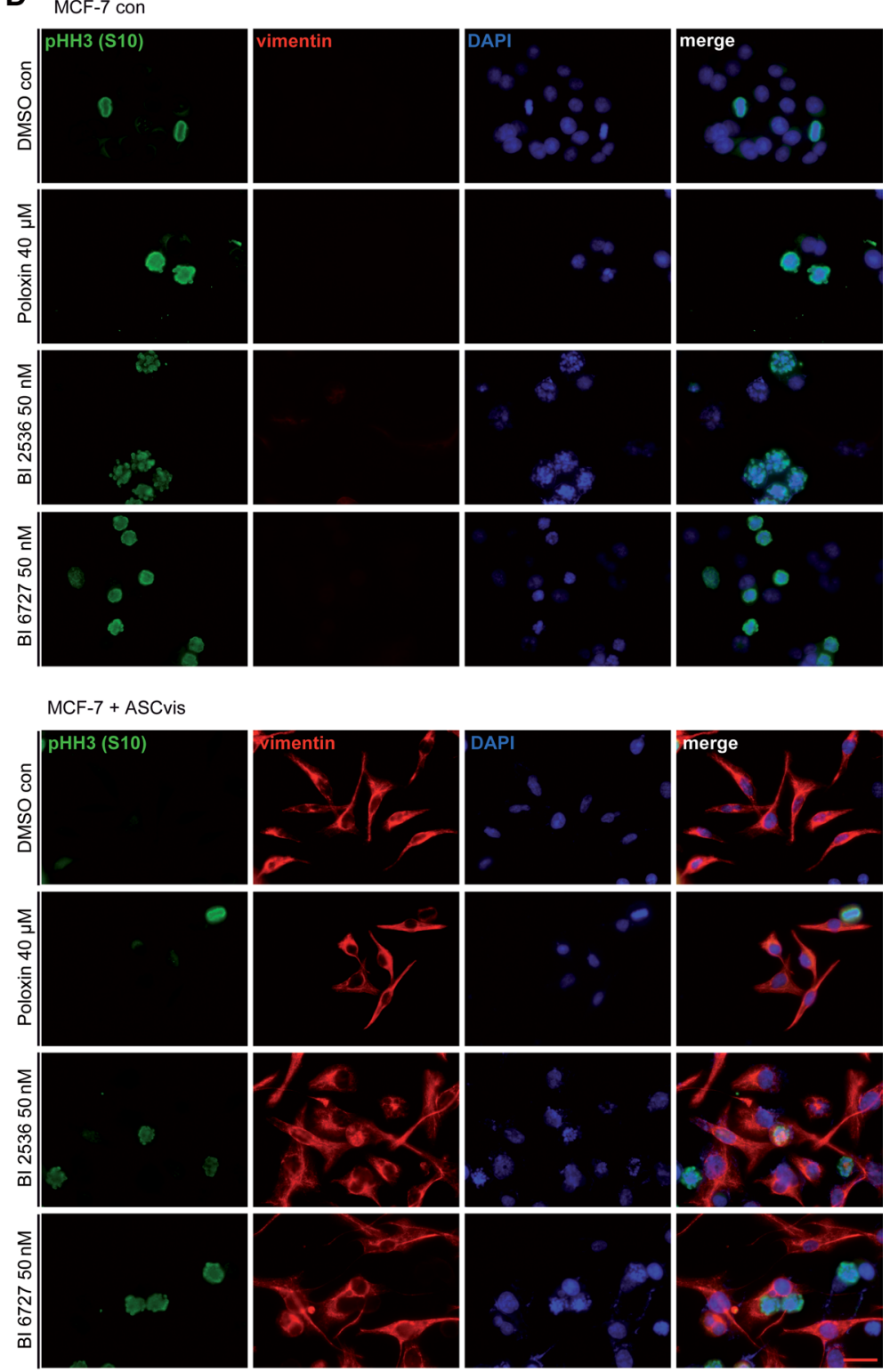

Figure 7: EMT-like MCF-7 cells are resistant to BI compounds. A.-C. Cell viability assay. MCF-7 cells A., MCF-7 cells incubated with visceral ASCs for 14 days B. and visceral ASCs alone C. were seeded in 96-well plates and treated with Plk1 inhibitors BI $2536(50 \mathrm{nM})$, BI $6727(50 \mathrm{nM})$ or Poloxin $(40 \mu \mathrm{M})$ and their viability was measured at indicated time points via CellTiter-Blue ${ }^{\circledR}$ assay. DMSO treated cells served as vehicle control. The results are obtained from three independent experiments with ASCs obtained from three different donors and presented as mean $\pm \operatorname{SEM}(n=3) .{ }^{*} p<0.05,{ }^{* *} p<0.01,{ }^{* * *} p<0.001$. D. The treated cells were stained for pHH3 (S10), vimentin and DNA. The representatives are shown (upper panel: MCF-7 control cells; lower panel: MCF-7 cells co-cultured with visceral ASCs). Scale bar: $25 \mu \mathrm{m}$. E. Quantification of positive pHH3 (S10) staining in MCF-7 control cells or in mesenchymal-like MCF-7 cells treated with BI compounds for $48 \mathrm{~h}$. The results are from three independent experiments with ASCs from three different donors and presented as mean $\pm \operatorname{SD}(n=3) . * p<0.05, * * p<0.01$. 
and in visceral adipose tissue, exert definitely distinct physiological functions [40]. The data might imply diverse roles of these ASCs in vivo: subcutaneous ASCs could be more mobile functioning in far organs and places, whereas visceral ASCs could work more locally in near areas. Despite differing in time and in efficiency, nevertheless, both ASCs differentiate into other cells types, home toward cancer cells and establish direct cell-cell contacts. Additionally, both ASCs secret various factors involved in autocrine and paracrine regulation and linked to tumor initiation, growth and metastasis [41].

Furthermore, we show that, in a direct co-culture manner, visceral ASCs promote proliferation of the low malignant breast cancer line MCF-7, but hardly affect the cell viability of the invasive breast cancer cell line MDAMB-231. Compared to visceral ASCs, subcutaneous ASCs are much less competent to stimulate proliferation of MCF-7 cells and even weakly inhibit expansion of MDA-MB-231 cells. Interestingly, both ASCs impact also slightly proliferation of normal mammary epithelial cells MCF-10A. The reduced effect of subcutaneous ASCs might be explained by a reduced expression of various cytokines like IL-6 and IL-8 known to be involved in breast cancer proliferation $[42,43]$. The immovableness of MDA-MB-231 cells could be due to their receptor composition, the negative expression of ER, PR and HER2 [16], in line with the notion that triple negative breast cancer cells respond differently to Notch, Hedgehog, Wnt $/ \beta$-catenin and TGF $\beta$ signaling pathways [44], which are activated by ASCs $[45,46]$. Furthermore, direct cellcell incubation induces an upregulation of mitotic genes Aurora B and Plk1, cytokine genes IL-6 and IL- 8 and the oncogene BCL6 known for their tumor promoting functions [17, 42, 47]. Intriguingly, indirect incubation via a transwell system seems to be inefficient to promote proliferation, indicating that a direct cell-cell contact, possibly combined with the extracellular matrix associated growth factors, is required for an effective proliferation.

Moreover, our results reveal that, despite varied capability, both types of ASCs are able to induce EMT in breast cancer cells by indirect co-culturing. This process is illustrated by a changed morphology, altered cytoskeleton composition and a reduced proliferation rate. Along with the modification of the cytoskeleton, the mRNA levels of BCL6, IL-6, IL-8 and IL-10 are highly increased, which are all well documented to induce EMT by multiple pathways in diverse cell lines [47-50]. Of note, we show that BCL6, a crucial player involved in $\mathrm{B}$ cell-lymphoma [51], is increased in MCF-7 cells upon direct co-incubation with ASCs promoting proliferation, as described above, and upon indirect co-culture in a transwell system with ASCs facilitating EMT in MCF7 cells. In line with previous observation [52], our data highlight that BCL6 is pivotal in progression of breast cancer cells stimulated by ASCs. Furthermore, Western blot analyses with lysates from mesenchymal-like MCF-
7 cells display increased activation of the PI3K/AKT, ERK1/2 and p-FAK pathways, together with enhanced expression of the transcription factors Snail, Slug and STAT3, also known as key players in the EMT process [53]. The results from treatment with kinase inhibitors suggest that the PI3K/AKT pathway is required for the EMT induced by ASCs, whereas the MAPK pathway seems to be dispensable for this process unlike reported for human lens epithelial cells or ovarian cancer cells $[54,55]$. Consequently, the EMT-like MCF-7 cells show a reinforced migration and invasion potential, and confer resistance to Plk1 inhibitors BI 2536 and BI 6727, in accordance with previous reports showing resistance to other chemotherapeutic drugs [56]. Along with EMT, MCF-7 cells express high levels of CD73 and CD90, two cell surface markers of mesenchymal stem cells, supporting the correlation between EMT and stemness [57]. Our results also suggest that low malignant breast cancer lines such as MCF-7 will be strongly impacted by ASCs, which enforce them into a more aggressive phenotype. In addition, subcutaneous ASCs, isolated from donors undergoing cesarean section, appear to be less competent in this study regarding their ability to promote proliferation and induce EMT in breast cancer cells. It has been reported that the reproductive state of donors hardly impacted the features of ASCs [58], it is still conceivable that various alterations in the pregnancy, like hormones, growth factors and metabolism, could affect ASCs and subsequently change their abilities. Further investigations are required to address this issue.

In summary, we demonstrate pro-tumorigenic effects of paired visceral and subcutaneous ASCs on proliferation, migration and invasion behavior of various cancer-derived cell lines. The interactions of ASCs with breast cancer cells, via direct cell-cell communication or indirect connection by secreting various cytokines, chemokines and growth factors, increase the expression of diverse cytokines, transcription factors and cell-surface proteins, induce EMT in breast cancer cells via activating multiple signaling pathways and render them resistant to Plk1 inhibition. More preclinical investigations are warranted to clarify these pro-tumorigenic effects of ASCs in more molecular depth. In parallel, more clinical studies with prolonged follow-up are required to address cancer recurrence in patients treated with ASC-enriched fat grafts.

\section{MATERIALS AND METHODS}

\section{Human adipose-derived stem cell (ASC) isolation, cell culture, differentiation and inhibitors}

Ethics approval was obtained from the Ethics Committee of the university Hospital Frankfurt and informed written consent was obtained from all donors. 
Visceral (omental) and subcutaneous (abdominal) adipose tissues were taken from women undergoing cesarean section. ASCs were isolated as described [11] with modifications. In brief, obtained visceral and subcutaneous adipose tissues were immediately washed, minced to small pieces, and digested with $1 \mathrm{mg} / \mathrm{ml}$ collagenase type I for $1 \mathrm{~h}$ at $37^{\circ} \mathrm{C}$. Cells were pelleted by centrifugation at 700 $\mathrm{g}$ for $10 \mathrm{~min}$ and the remaining blood cells were lysed by addition of red blood cell lysis buffer $\left(155 \mathrm{mM} \mathrm{NH}_{4} \mathrm{Cl}\right.$, $10 \mathrm{mM} \mathrm{KHCO}_{3}$, and $0.1 \mathrm{mM} \mathrm{EDTA}$ ) for $10 \mathrm{~min}$ at $37^{\circ} \mathrm{C}$. To remove the lysis buffer cells were centrifuged at 700 $\mathrm{g}$ for $10 \mathrm{~min}$ and filtered through a $100-\mathrm{m}$ mesh filter to remove undigested adipose tissue. The remaining cells were centrifuged, seeded onto 6-cm cell cultures plates in DMEM containing 20\% fetal bovine serum (FBS), $100 \mathrm{~g} /$ $\mathrm{ml}$ streptomycin, $100 \mathrm{U} / \mathrm{ml}$ penicillin, $2 \mathrm{mM}$ l-glutamine, and $1 \mathrm{~g} / \mathrm{ml}$ amphotericin-B and cultured under standard cell culture conditions. After $24 \mathrm{~h}$, non-adherent cells were removed and the remaining cells were washed, cultured and expanded. Early passages (P2 to P5) of isolated ASCs were used for experiments.

To induce adipogenic differentiation, cells were cultured with StemMACS ${ }^{\mathrm{TM}}$ AdipoDiff Media (Miltenyi Biotec, Gladbach) for 14 days. Cells were then fixed and stained for oil red $\mathrm{O}$ and adiponectin characteristic of adipocytes. For osteogenic differentiation, ASCs were incubated in StemMACS ${ }^{\mathrm{TM}}$ OsteoDiff Media (Miltenyi Biotec) for 21 days, fixed and stained with 2\% Alizarin Red S ( $\mathrm{pH} 4.2$ ) to visualize calcific deposition by cells of an osteogenic lineage. For neurogenic differentiation, cells were cultured in DMEM supplemented with $5 \mathrm{mM} \mathrm{KCl,} 2$ $\mu \mathrm{M}$ valproic acid, $10 \mu \mathrm{M}$ forskolin, $1 \mu \mathrm{M}$ hydrocortisone, $5 \mu \mathrm{g} / \mathrm{ml}$ insulin, $0.5 \%$ ethanol and $200 \mu \mathrm{M}$ butylated hydroxyanisole for 21 days, and cells were stained for class III beta-tubulin and doublecortin.

MCF-7, MDA-MB-231 and MCF-10A were obtained from ATCC and skin fibroblasts were a kind gift from our Department of Dermatology, Frankfurt. All cells were cultured as instructed. BI 2536 and BI 6727 were purchased from Selleck Chemicals LLC (Houston) and Poloxin was kindly provided by Dr. Berg (Leipzig University). DMSO was from SigmaAldrich (Taufkirchen), PD98059 from Merck Millipore (Darmstadt) and Wortmannin from Cell Signaling (Beverly).

\section{Cellular extract preparation, western blot analysis and cytokine array}

Cellular lysates were prepared using RIPA buffer (50 mM Tris pH 8.0, $150 \mathrm{mM} \mathrm{NaCl}, 1 \% \mathrm{NP}-40,0.5 \%$ Na-desoxycholate, $0.1 \%$ SDS, $1 \mathrm{mM} \mathrm{NaF}, 1 \mathrm{mM}$ DTT, phosphatase and protease inhibitor cocktail tablets (Roche, Mannheim)). Western blot analysis was performed as previously described $[59,60]$. Following antibodies were used: Rabbit polyclonal antibodies against AKT, phosphoAKT (S473), phospho-FAK (Y397), STAT3 and phosphoSTAT3 (Y705) (Cell Signaling), rabbit monoclonal antibodies against E-cadherin, N-cadherin, Slug and Snail (Cell Signaling), mouse monoclonal antibody against $\beta$-actin (Sigma-Aldrich), mouse monoclonal antibodies against BCL6 and vimentin (Dako, Hamburg), rabbit polyclonal antibody against ERK1/2 and rabbit monoclonal antibody against phospho-ERK1/2 (T202/ Y204) (Merck Millipore, Darmstadt), rabbit monoclonal antibody against fibronectin and rabbit polyclonal antibody against IL-6 (Abcam, Cambridge).

For cytokine measurement in supernatants, visceral and subcutaneous ASC in passage 1 were cultured for 3 days to a confluence of $90 \%$. The levels of chemokines, cytokines and growth factors in the culture media were determined by a human cytokine antibody array according to the manufacturer's instructions (Abcam). The chemiluminescent membranes were developed using the ChemiDoc ${ }^{\mathrm{TM}}$ MP System (Bio-Rad, Munich) and the signal intensity was assessed with ImageJ 1.49i software (National Institutes of Health, USA) by determining the pixel intensity of the detected spots.

\section{Indirect immunofluorescence}

Cells were seeded on Nunc ${ }^{\mathrm{TM}} \mathrm{Lab}^{-\mathrm{Tek}^{\mathrm{TM}}}$ SlideFlask chambers from Thermo Fisher Scientific (Schwerte). Immunofluorescence staining was performed as described [61-63]. Briefly, cells were fixed for 10 min with methanol at $-20^{\circ} \mathrm{C}$ or with $4 \%$ paraformaldehyde containing $0.1 \%$ Triton $^{\mathrm{TM}} \mathrm{X}-100$ for $15 \mathrm{~min}$ at room temperature. The following primary antibodies were used for staining: monoclonal mouse antibody against FITC-conjugated $\alpha$-tubulin and mouse monoclonal antibody against acetylated $\alpha$-tubulin (Sigma-Aldrich), rabbit polyclonal antibodies against pericentrin, mouse monoclonal antibody against adiponectin and rabbit monoclonal antibodies against CD90, E-cadherin and $\mathrm{N}$-cadherin (Abcam), mouse monoclonal antibody against DCX, rabbit polyclonal antibody against CD73 and chicken polyclonal antibody against Tuj1 (GeneTex), mouse monoclonal antibody against vimentin (Dako), mouse monoclonal antibody against pHH3 (S10) (Merck Millipore), rabbit polyclonal antibody against phospho-FAK (Y397) (Cell Signaling), rat monoclonal antibody against $\alpha$-tubulin (Biomol, Hamburg) and mouse monoclonal antibodies against CD14 and CD31 (Biolegend, Fell). Filamentous actin was stained using phalloidin-TRITC (Sigma-Aldrich) and DNA was visualized by using DAPI (4',6-diamidino2-phenylindole-dihydrochloride, Roche, Mannheim). The immunofluorescence slides were examined using an AxioObserver.Z1 microscope (Zeiss, Göttingen) or by a confocal laser scanning microscope (CLSM, Leica CTR 6500, Heidelberg).

For flow cytometry, cells were harvested with 0.25 
$\%$ trypsin, fixed for 15 min with ice-cold $2 \%$ PFA at $4{ }^{\circ} \mathrm{C}$. Cells were washed twice with FCB (PBS, 0.2\% Tween-20, $2 \% \mathrm{FCS}$ ) and stained with the following antibodies from eBioscience (Frankfurt am Main): FITC-conjugated antihuman CD90, PerCP-Cy5.5-conjugated anti-human CD90, PE-conjugated anti-human CD14, FITC-conjugated anti-human CD34, PerCP-Cy5.5-conjugated anti-human CD146, APC-conjugated anti-human CD106 and APCconjugated anti-human CD31.

\section{Cell proliferation and flow cytometry}

Cell proliferation assays were performed by using Cell Titer-Blue ${ }^{\circledR}$ Cell Viability Assay (Promega, Mannheim) as described [32]. The ratio 1:5 between ASCs and cancer cells was used for direct co-culture experiments. MCF-7 and MDA-MB-231 cells were stably transfected with Ruby-H2B or EGFP-H2B and selected with geneticin (Sigma-Aldrich). The stable cell lines were verified by flow cytometry. Both cell lines were cocultured with ASCs (5:1 ratio) in a 6-cm culture dish. After five days, cells were analyzed using a FACSCalibur ${ }^{\mathrm{TM}}$ (BD Bioscience, Heidelberg). The percentages of EGFP or Ruby positive cancer cells were determined with BD CellQuest ${ }^{\mathrm{TM}}$ Pro software (BD Bioscience).

To evaluate the mitotic fraction, $\mathrm{MCF}-7$ cells and MCF-7 cells indirectly co-cultivated with visceral ASCs for 14 days, were seeded into slide flask chambers. After 8 $\mathrm{h}$ the cells were treated with $50 \mathrm{nM}$ BI 2536 or $50 \mathrm{nM} \mathrm{BI}$ 6727 for 48 h. Cells were stained for phospho-histone H3 (pHH3, S10). Five pictures of each slide flask were taken and the experiments were performed in triplicate. The percentage of positive $\mathrm{pHH} 3$ (S10) cells were evaluated using the AxioVision SE64 Re. 4.9 software (Zeiss).

\section{Migration, invasion and attraction assay}

Cell migration assays were performed with culture-inserts from ibidi (Martinsried). Culture-inserts (cell free gap of $500 \mu \mathrm{m}$ ) were placed in a 6-cm culture dish and both wells of each insert were filled with cell suspension. MCF-7 (6.5 x 104), MDA-MB-231 $\left(5.5 \times 10^{4}\right)$, fibroblasts $\left(6.5 \times 10^{4}\right)$ and MCF-10A $(5 \times$ $10^{4}$ ) cells were seeded in each well of the culture-inserts, which were surrounded by visceral or subcutaneous ASCs. Culture-inserts were gently removed after at least $8 \mathrm{~h}$. The cells were acquired and imaged at indicated time points with bright-field images. Four pictures of each insert were taken and the experiments were performed in triplicate. The open area was measured using the AxioVision SE64 Re. 4.9 software (Zeiss).

For attraction assay, cells were placed in a $6-\mathrm{cm}$ culture dish and one well of each insert was filled with cell suspensions either with visceral or subcutaneous ASCs $\left(5.5 \times 10^{4}\right)$ or with the investigated cells (MCF-7, MDA-
MB-231, fibroblasts or MCF-10A). After $8 \mathrm{~h}$, the cultureinserts were removed and the images were obtained at indicated time points. Cellular movement toward other migration front was evaluated using the AxioVision SE64 Re. 4.9 software (Zeiss). The experiments were independently performed three times.

For invasion assay, MCF-7 and MDA-MB-231 cells were indirectly co-cultured with visceral ASCs in a transwell chamber for at least 14 days. Cells were then seeded in 24-well transwell matrigel chambers according to the manufacturer's instructions (Cell Biolabs Inc, San Diego) and as previously reported [26]. Briefly, cells (MDA-MB-231, $7.5 \times 10^{4}$; MCF-7, $12 \times 10^{4}$ ) were seeded into the upper chamber of the transwell in $500 \mu 1$ serumfree medium and the lower chamber was filled with 750 $\mu \mathrm{l}$ serum-free medium. After $12 \mathrm{~h}$ the medium of both chambers was discarded and the invasion assay was started by adding medium containing $10 \%$ fetal bovine serum for the next $24 \mathrm{~h}$. Cells were fixed with ethanol and stained with DAPI. Invaded cells were counted with a microscope. The experiments were independently performed three times.

\section{RNA extraction and real-time PCR}

Total RNAs of ASCs and cancer cells were extracted with RNeasy kits with column DNase digestion according to the manufacturer's instructions (QIAGEN, Hilden). Reverse transcription was performed using High-Capacity cDNA Reverse Transcription Kit (Applied Biosystems, Darmstadt) as instructed. The probes for Aurora A, Aurora B, BCL6, cyclin B1, IL-6, IL-8, IL-10, p21 and Plk1 were obtained from Applied Biosystems. Real-time PCR was performed with a StepOnePlus Real-time PCR System (Applied Biosystems). The data were analyzed using StepOne Software v.2.3 (Applied Biosystems) as described previously $[60,64]$ with two methods. First is the comparative $\mathrm{Ct}$ method: the relative quantity of target gene expression is determined by comparing a reference sample and an endogenous control to the target sample. This method displays the gene expression as $\Delta \mathrm{Ct}$ value, which is normalized to endogenous GAPDH and is reversely related to the amount of target mRNA. Second is the standard curve method which uses standards to determine the absolute quantity of target gene expression.

\section{Statistical analysis}

Student's $t$-test (two tailed and paired or homoscedastic) was used to evaluate the significance of difference between different groups. Difference was considered as statistically significant when $p<0.05$. 


\section{Abbreviations}

ASC, adipose-derived stem cell; MSC, mesenchymal stem cell; IL, interleukin; PI3K, phosphatidylinositol 3-kinase; BCL6, B-cell lymphoma 6; MAPK, mitogenactivated protein kinase; EMT, epithelial-to-mesenchymal transition.

\section{ACKNOWLEDGMENTS}

We are grateful to our patients for making this study possible and to our clinical team for their assistance in collecting tissue samples. We thank Prof. Dr. T. Berg (Leipzig University) for kindly providing Poloxin. We thank Ms. S. Roth for excellent technical assistance. We are thankful to all members of our lab for helpful discussions, especially Dr. NN. Kreis for critical reading and comments on this manuscript.

\section{CONFLICTS OF INTEREST}

The authors declare no conflicts of interest.

\section{REFERENCES}

1. Ferlay J, Soerjomataram I, Dikshit R, Eser S, Mathers C, Rebelo M, Parkin DM, Forman D and Bray F. Cancer incidence and mortality worldwide: sources, methods and major patterns in GLOBOCAN 2012. International journal of cancer Journal international du cancer. 2015; 136(5):E359-386.

2. Hanahan D and Coussens LM. Accessories to the crime: functions of cells recruited to the tumor microenvironment. Cancer cell. 2012; 21:309-322.

3. Pittenger MF, Mackay AM, Beck SC, Jaiswal RK, Douglas R, Mosca JD, Moorman MA, Simonetti DW, Craig S and Marshak DR. Multilineage potential of adult human mesenchymal stem cells. Science. 1999; 284:143-147.

4. Harasymiak-Krzyzanowska I, Niedojadlo A, Karwat J, Kotula L, Gil-Kulik P, Sawiuk M and Kocki J. Adipose tissue-derived stem cells show considerable promise for regenerative medicine applications. Cellular \& molecular biology letters. 2013; 18:479-493.

5. Calis M, Demirtas TT, Atilla P, Tatar I, Ersoy O, Irmak G, Celik HH, Cakar AN, Gumusderelioglu M and Ozgur F. Estrogen as a novel agent for induction of adipose-derived mesenchymal stem cells for osteogenic differentiation: in vivo bone tissue-engineering study. Plastic and reconstructive surgery. 2014; 133:499e-510e.

6. Donnenberg VS, Zimmerlin L, Rubin JP and Donnenberg AD. Regenerative therapy after cancer: what are the risks? Tissue engineering Part B, Reviews. 2010; 16:567-575.

7. Freese KE, Kokai L, Edwards RP, Philips BJ, Sheikh MA, Kelley J, Comerci J, Marra KG, Rubin JP and Linkov
F. Adipose-derived stems cells and their role in human cancer development, growth, progression, and metastasis: a systematic review. Cancer Res. 2015; 75:1161-1168.

8. Chandler EM, Seo BR, Califano JP, Andresen Eguiluz RC, Lee JS, Yoon CJ, Tims DT, Wang JX, Cheng L, Mohanan S, Buckley MR, Cohen I, Nikitin AY, Williams RM, Gourdon D, Reinhart-King CA, et al. Implanted adipose progenitor cells as physicochemical regulators of breast cancer. Proceedings of the National Academy of Sciences of the United States of America. 2012; 109:9786-9791.

9. Cousin B, Ravet E, Poglio S, De Toni F, Bertuzzi M, Lulka H, Touil I, Andre M, Grolleau JL, Peron JM, Chavoin JP, Bourin P, Penicaud L, Casteilla L, Buscail L and Cordelier P. Adult stromal cells derived from human adipose tissue provoke pancreatic cancer cell death both in vitro and in vivo. PLoS One. 2009; 4:e6278.

10. Ryu H, Oh JE, Rhee KJ, Baik SK, Kim J, Kang SJ, Sohn JH, Choi E, Shin HC, Kim YM, Kim HS, Bae KS and Eom YW. Adipose tissue-derived mesenchymal stem cells cultured at high density express IFN-beta and suppress the growth of MCF-7 human breast cancer cells. Cancer Lett. 2014; 352:220-227.

11. Baglioni S, Francalanci M, Squecco R, Lombardi A, Cantini G, Angeli R, Gelmini S, Guasti D, Benvenuti S, Annunziato F, Bani D, Liotta F, Francini F, Perigli G, Serio $\mathrm{M}$ and Luconi M. Characterization of human adult stemcell populations isolated from visceral and subcutaneous adipose tissue. FASEB journal : official publication of the Federation of American Societies for Experimental Biology. 2009; 23:3494-3505.

12. Dominici M, Le Blanc K, Mueller I, Slaper-Cortenbach I, Marini F, Krause D, Deans R, Keating A, Prockop D and Horwitz E. Minimal criteria for defining multipotent mesenchymal stromal cells. The International Society for Cellular Therapy position statement. Cytotherapy. 2006; 8:315-317.

13. Ranganath SH, Levy O, Inamdar MS and Karp JM. Harnessing the mesenchymal stem cell secretome for the treatment of cardiovascular disease. Cell stem cell. 2012; 10:244-258.

14. Huang W, Chen Z, Zhang L, Tian D, Wang D, Fan D, Wu $\mathrm{K}$ and Xia L. Interleukin-8 Induces Expression of FOXC1 to Promote Trans-activation of CXCR1 and CCL2 in Hepatocellular Carcinoma Cell Lines and Formation of Metastases in Mice. Gastroenterology. 2015;149:10531067.

15. Choi SA, Lee YE, Kwak PA, Lee JY, Kim SS, Lee SJ, Phi JH, Wang KC, Song J, Song SH, Joo KM and Kim SK. Clinically applicable human adipose tissue-derived mesenchymal stem cells delivering therapeutic genes to brainstem gliomas. Cancer gene therapy. 2015; 22:302-311.

16. Subik K, Lee JF, Baxter L, Strzepek T, Costello D, Crowley P, Xing L, Hung MC, Bonfiglio T, Hicks DG and Tang P. The Expression Patterns of ER, PR, HER2, CK5/6, EGFR, Ki-67 and AR by Immunohistochemical Analysis in Breast 
Cancer Cell Lines. Breast cancer : basic and clinical research. 2010; 4:35-41.

17. Wei HJ, Zeng R, Lu JH, Lai WF, Chen WH, Liu HY, Chang YT and Deng WP. Adipose-derived stem cells promote tumor initiation and accelerate tumor growth by interleukin-6 production. Oncotarget. 2015; 6:7713-7726.

18. Albagli-Curiel O. Ambivalent role of BCL6 in cell survival and transformation. Oncogene. 2003; 22:507-516.

19. Waugh DJ and Wilson C. The interleukin-8 pathway in cancer. Clinical cancer research : an official journal of the American Association for Cancer Research. 2008; 14:67356741.

20. Tsai JH and Yang J. Epithelial-mesenchymal plasticity in carcinoma metastasis. Genes \& development. 2013; 27:2192-2206.

21. Evdokimova V, Tognon C, Ng T and Sorensen PH. Reduced proliferation and enhanced migration: two sides of the same coin? Molecular mechanisms of metastatic progression by YB-1. Cell cycle. 2009; 8:2901-2906.

22. Tsai JH, Donaher JL, Murphy DA, Chau S and Yang J. Spatiotemporal regulation of epithelial-mesenchymal transition is essential for squamous cell carcinoma metastasis. Cancer cell. 2012; 22:725-736.

23. Lamouille S, Xu J and Derynck R. Molecular mechanisms of epithelial-mesenchymal transition. Nature reviews Molecular cell biology. 2014; 15:178-196.

24. Arcaro A and Wymann MP. Wortmannin is a potent phosphatidylinositol 3-kinase inhibitor: the role of phosphatidylinositol 3,4,5-trisphosphate in neutrophil responses. Biochem J. 1993; 296 :297-301.

25. Alessi DR, Cuenda A, Cohen P, Dudley DT and Saltiel AR. PD 098059 is a specific inhibitor of the activation of mitogen-activated protein kinase kinase in vitro and in vivo. J Biol Chem. 1995; 270:27489-27494.

26. Ritter A, Sanhaji M, Friemel A, Roth S, Rolle U, Louwen $\mathrm{F}$ and Yuan J. Functional analysis of phosphorylation of the mitotic centromere-associated kinesin by Aurora B kinase in human tumor cells. Cell cycle. 2015:0.

27. Polyak K and Weinberg RA. Transitions between epithelial and mesenchymal states: acquisition of malignant and stem cell traits. Nature reviews Cancer. 2009; 9:265-273.

28. Lobba AR, Forni MF, Carreira AC and Sogayar MC. Differential expression of CD90 and CD14 stem cell markers in malignant breast cancer cell lines. Cytometry Part A : the journal of the International Society for Analytical Cytology. 2012; 81:1084-1091.

29. Gao ZW, Dong K and Zhang HZ. The roles of CD73 in cancer. BioMed research international. 2014; 2014:460654.

30. Mitra A, Mishra L and Li S. EMT, CTCs and CSCs in tumor relapse and drug-resistance. Oncotarget. 2015; 6:10697-10711.

31. Sanhaji M, Kreis NN, Zimmer B, Berg T, Louwen F and Yuan J. p53 is not directly relevant to the response of Pololike kinase 1 inhibitors. Cell cycle. 2012; 11:543-553.
32. Kreis NN, Louwen F, Zimmer B and Yuan J. Loss of p21Cip1/CDKN1A renders cancer cells susceptible to Pololike kinase 1 inhibition. Oncotarget. 2015; 6:6611-6626.

33. Yang Y, Bucan V, Baehre H, von der Ohe J, Otte A and Hass R. Acquisition of new tumor cell properties by MSCderived exosomes. Int J Oncol. 2015; 47:244-252.

34. Orecchioni S, Gregato G, Martin-Padura I, Reggiani F, Braidotti P, Mancuso P, Calleri A, Quarna J, Marighetti P, Aldeni C, Pruneri G, Martella S, Manconi A, Petit JY, Rietjens $\mathrm{M}$ and Bertolini F. Complementary populations of human adipose CD34+ progenitor cells promote growth, angiogenesis, and metastasis of breast cancer. Cancer Res. 2013; 73:5880-5891.

35. Zhao M, Sachs PC, Wang X, Dumur CI, Idowu MO, Robila V, Francis MP, Ware J, Beckman M, Rizki A, Holt SE and Elmore LW. Mesenchymal stem cells in mammary adipose tissue stimulate progression of breast cancer resembling the basal-type. Cancer biology \& therapy. 2012; 13:782-792.

36. Muehlberg FL, Song YH, Krohn A, Pinilla SP, Droll LH, Leng X, Seidensticker M, Ricke J, Altman AM, Devarajan E, Liu W, Arlinghaus RB and Alt EU. Tissue-resident stem cells promote breast cancer growth and metastasis. Carcinogenesis. 2009; 30:589-597.

37. Qiao L, Xu ZL, Zhao TJ, Ye LH and Zhang XD. Dkk-1 secreted by mesenchymal stem cells inhibits growth of breast cancer cells via depression of Wnt signalling. Cancer Lett. 2008; 269:67-77.

38. Sun B, Roh KH, Park JR, Lee SR, Park SB, Jung JW, Kang SK, Lee YS and Kang KS. Therapeutic potential of mesenchymal stromal cells in a mouse breast cancer metastasis model. Cytotherapy. 2009; 11:289-298, 281 p following 298.

39. Chau YY, Bandiera R, Serrels A, Martinez-Estrada OM, Qing W, Lee M, Slight J, Thornburn A, Berry R, McHaffie S, Stimson RH, Walker BR, Chapuli RM, Schedl A and Hastie N. Visceral and subcutaneous fat have different origins and evidence supports a mesothelial source. Nat Cell Biol. 2014; 16:367-+.

40. Ibrahim MM. Subcutaneous and visceral adipose tissue: structural and functional differences. Obesity reviews : an official journal of the International Association for the Study of Obesity. 2010; 11:11-18.

41. Schweizer R, Tsuji W, Gorantla VS, Marra KG, Rubin JP and Plock JA. The role of adipose-derived stem cells in breast cancer progression and metastasis. Stem cells international. 2015; 2015:120949.

42. Wang Y, Xu RC, Zhang XL, Niu XL, Qu Y, Li LZ and Meng XY. Interleukin-8 secretion by ovarian cancer cells increases anchorage-independent growth, proliferation, angiogenic potential, adhesion and invasion. Cytokine. 2012; 59:145-155.

43. Chou CH, Lai SL, Chen CN, Lee PH, Peng FC, Kuo ML and Lai HS. IL-6 regulates Mcl-1L expression through the JAK/PI3K/Akt/CREB signaling pathway in hepatocytes: 
implication of an anti-apoptotic role during liver regeneration. PLoS One. 2013; 8:e66268.

44. Jamdade VS, Sethi N, Mundhe NA, Kumar P, Lahkar M and Sinha N. Therapeutic Targets of Triple Negative Breast Cancer: A Review. British journal of pharmacology. 2015; 172:4228-37.

45. Pallua N, Serin M and Wolter TP. Characterisation of angiogenetic growth factor production in adipose tissuederived mesenchymal cells. Journal of plastic surgery and hand surgery. 2014; 48:412-416.

46. Lin R, Wang S and Zhao RC. Exosomes from human adipose-derived mesenchymal stem cells promote migration through Wnt signaling pathway in a breast cancer cell model. Molecular and cellular biochemistry. 2013; 383:1320.

47. Yu JM, Sun W, Hua F, Xie J, Lin H, Zhou DD and Hu ZW. BCL6 induces EMT by promoting the ZEB1-mediated transcription repression of E-cadherin in breast cancer cells. Cancer Lett. 2015; 365:190-200.

48. Xie G, Yao Q, Liu Y, Du S, Liu A, Guo Z, Sun A, Ruan J, Chen L, Ye C and Yuan Y. IL-6-induced epithelialmesenchymal transition promotes the generation of breast cancer stem-like cells analogous to mammosphere cultures. Int J Oncol. 2012; 40:1171-1179.

49. Yin J, Zeng F, Wu N, Kang K, Yang Z and Yang $\mathrm{H}$. Interleukin-8 promotes human ovarian cancer cell migration by epithelial-mesenchymal transition induction in vitro. Clinical \& translational oncology : official publication of the Federation of Spanish Oncology Societies and of the National Cancer Institute of Mexico. 2015; 17:365-370.

50. Liu CY, Xu JY, Shi XY, Huang W, Ruan TY, Xie P and Ding JL. M2-polarized tumor-associated macrophages promoted epithelial-mesenchymal transition in pancreatic cancer cells, partially through TLR4/IL-10 signaling pathway. Laboratory investigation; a journal of technical methods and pathology. 2013; 93:844-854.

51. Crotty S, Johnston RJ and Schoenberger SP. Effectors and memories: Bcl-6 and Blimp-1 in T and B lymphocyte differentiation. Nature immunology. 2010; 11:114-120.

52. Walker SR, Liu S, Xiang M, Nicolais M, Hatzi K, Giannopoulou E, Elemento O, Cerchietti L, Melnick A and Frank DA. The transcriptional modulator BCL6 as a molecular target for breast cancer therapy. Oncogene. 2015; 34:1073-1082.

53. Tao D, Pan Y, Jiang G, Lu H, Zheng S, Lin H and Cao F. $\mathrm{B}-\mathrm{Myb}$ regulates snail expression to promote epithelial-tomesenchymal transition and invasion of breast cancer cell. Medical oncology. 2015; 32:412.

54. Liu L, Zhang J, Fang C, Zhang Z, Feng Y and Xi X. OCT4 mediates FSH-induced epithelial-mesenchymal transition and invasion through the ERK1/2 signaling pathway in epithelial ovarian cancer. Biochemical and biophysical research communications. 2015; 461:525-532.

55. Chen X, Ye S, Xiao W, Wang W, Luo L and Liu Y. ERK1/2 pathway mediates epithelial-mesenchymal transition by cross-interacting with TGFbeta/Smad and Jagged/Notch signaling pathways in lens epithelial cells. International journal of molecular medicine. 2014; 33:1664-1670.

56. Holohan C, Van Schaeybroeck S, Longley DB and Johnston PG. Cancer drug resistance: an evolving paradigm. Nature reviews Cancer. 2013; 13:714-726.

57. Schmidt JM, Panzilius E, Bartsch HS, Irmler M, Beckers J, Kari V, Linnemann JR, Dragoi D, Hirschi B, Kloos UJ, Sass S, Theis F, Kahlert S, Johnsen SA, Sotlar K and Scheel $\mathrm{CH}$. Stem-cell-like properties and epithelial plasticity arise as stable traits after transient Twist1 activation. Cell reports. 2015; 10:131-139.

58. Ng LW, Yip SK, Wong HK, Yam GH, Liu YM, Lui WT, Wang CC and Choy KW. Adipose-derived stem cells from pregnant women show higher proliferation rate unrelated to estrogen. Human reproduction. 2009; 24:1164-1170.

59. Kreis NN, Sommer K, Sanhaji M, Kramer A, Matthess Y, Kaufmann M, Strebhardt K and Yuan J. Long-term downregulation of Polo-like kinase 1 increases the cyclindependent kinase inhibitor p21(WAF1/CIP1). Cell cycle. 2009; 8:460-472.

60. Muschol-Steinmetz C, Friemel A, Kreis NN, Reinhard J, Yuan J and Louwen F. Function of survivin in trophoblastic cells of the placenta. PLoS One. 2013; 8:e73337.

61. Sanhaji M, Friel CT, Kreis NN, Kramer A, Martin C, Howard J, Strebhardt K and Yuan J. Functional and spatial regulation of mitotic centromere-associated kinesin by cyclin-dependent kinase 1. Molecular and cellular biology. 2010; 30:2594-2607.

62. Sanhaji M, Ritter A, Belsham HR, Friel CT, Roth S, Louwen F and Yuan J. Polo-like kinase 1 regulates the stability of the mitotic centromere-associated kinesin in mitosis. Oncotarget. 2014; 5:3130-3144.

63. Ritter A, Sanhaji M, Steinhauser K, Roth S, Louwen F and Yuan J. The activity regulation of the mitotic centromereassociated kinesin by Polo-like kinase 1. Oncotarget. 2015; 6:6641-6655.

64. Louwen F, Muschol-Steinmetz C, Friemel A, Kampf AK, Tottel E, Reinhard J and Yuan J. Targeted gene analysis: increased B-cell lymphoma 6 in preeclamptic placentas. Human pathology. 2014; 45:1234-1242. 